\title{
Os contornos da cidadania crítica: explorando a legitimidade democrática ${ }^{7}$
}

\author{
Mitchel A. Seligson \\ University of Pittsburgh, Estados Unidos \\ John A. Booth \\ University of North Texas, Estados Unidos \\ Miguel Gómez B. \\ Universidad de Costa Rica, Costa Rica
}

\begin{abstract}
Resumo
Recentes quedas acentuadas da confiança no governo dos públicos de massa de democracias institucionalizadas reacenderam o interesse pela teoria e pesquisa sobre a legitimidade. Há muito tempo os teóricos concebem a legitimidade política como multidimensional e sustentam que ela vai do apoio abstrato a uma comunidade política subjacente aos princípios do regime à avaliação mais concreta do desempenho do regime, das instituições e dos atores. Porém, surpreendentemente, pouca pesquisa empírica avaliou a validade desse constructo teórico. Utilizando um survey nacional da Costa Rica, uma democracia estável e bem sucedida, investigamos se a legitimidade política existe empiricamente e examinamos sua estrutura. Usando análise fatorial confirmatória, encontramos evidências que sustentam a estrutura multidimensional do apoio político. Identificamos também certas limitações tanto da pesquisa teórica como da empírica, relacionadas com a operacionalização equivocada e a especificação de vínculos empíricos que não conseguimos detectar. Também encontramos e remediamos um surpreendente erro de omissão, já que as pesquisas anteriores não haviam percebido o governo local como um alvo de crenças legitimidoras.
\end{abstract}

Palavras-chave: legitimidade política, cultura política, democracia, confiança

\begin{abstract}
Recent steep declines in trust in government among the mass publics of institutionalized democracies have rekindled interest in legitimacy theory and research. Theorists have long conceived of political legitimacy as multidimensional, and argue that it ranges from abstract support for a political community underlying regime principles to the more concrete evaluation of regime performance, institutions, and actors. However, surprisingly little empirical research has evaluated the theory's construct validity. Employing a national sample survey from Costa Rican, a stable and successful democracy, we explore whether political legitimacy empirically exists and examine its structure. Using confirmatory factor analysis, we find evidence supporting the multidimensional structure of political support. We also identify certain limitations with both the theoretical and limited empirical research, related to misleading operationalization and the specification of empirical links that we fail to detect. We also find and remedy a surprising error of omission - that prior research overlooked local government as a target of legitimacy beliefs.
\end{abstract}

Key words: political legitimacy, civic culture, democracy, trust

\footnotetext{
${ }^{1}$ Os autores agradecem a Phil Paolino, Pippa Norris, Amber Seligson e aos vários pareceristas anônimos pelos comentários em versões anteriores deste artigo.
} 
A erosão da confiança no governo ameaça a legitimidade do governo, o verdadeiro alicerce da democracia. Gary Hart, ex-senador dos Estados Unidos²

A legitimidade política, que durante décadas foi um conceito fundamental para a ciência política e do qual jornalistas e diplomatas se apropriaram em seus discursos sobre os Estados-nações, passa por dificuldades. Muitos livros e artigos demonstraram empiricamente um acentuado e longo declínio da legitimidade política e uma onda crescente de cidadania crítica nas democracias industriais avançadas. Contudo, as terríveis conseqüências que decorrem da queda da legitimidade, previstas por obras seminais do campo, não ocorreram.

A teoria da legitimidade se reporta, com freqüência, à obra clássica de Lipset, Political man (1961). Lipset examinou o processo histórico, de longo prazo, pelo qual os regimes superam crises e se tornam sistemas políticos estáveis com legitimidade amplamente aceita. Todavia, nos Estados Unidos e em outras democracias estabelecidas, dados de surveys mostram que a confiança da população no governo, nos políticos e nas instituições públicas diminuiu acentuadamente, às vezes ao longo de décadas ${ }^{3}$. Estudiosos e figuras públicas deram repetidamente o alarme de que a própria democracia poderia ser posta em risco pelo declínio da legitimidade - ou seja, pelo crescimento da proporção de cidadãos críticos (KORNBERG e CLARKE, 1992; NYE, 1997; MILLER, 1974; NYE, ZELIKOW e KING, 1997; PRESTON et al., 1983; PHARR, PUTNAM e DALTON, 2000; DALTON, 2004).

Se a legitimidade é tão importante para a estabilidade política quanto a literatura clássica afirma, então sua erosão em muitas democracias contemporâneas deveria causar alguns efeitos. Como diz Dalton: "O afrouxamento dos laços com a comunidade política em um sistema democrático pode prenunciar uma eventual revolução, guerra civil ou colapso da democracia" (DALTON, 2004, p. 7).

\footnotetext{
2 Tal como citado na sobrecapa de Dalton (2004).

3 Ver a extensa bibliografia reunida por Norris (1999) e pelos colaboradores de seu livro Critical citizens: global support for democratic governance, e por Nye, Zelikow e King (1997) e seus colaboradores em Why people don't trust the government. Ver também Citrin (1974), Miller (1974), Finkel, Muller e Seligson (1989), Nye e Zelikow (1997), Gibson, Caldeira, e Spence (2003), Hardin (1999) e Warren (1999).
} 
No entanto, sabemos que, apesar do declínio do apoio de massa medido pelas pesquisas, as democracias industriais avançadas não parecem estar à beira do colapso e mesmo a atividade generalizada de protesto contra o sistema é rara 4 . Os tumultos de dezembro de 1999 em Seattle ocorreram de fato, e protestos similares aconteceram na Europa Ocidental, mas essas irrupções foram esporádicas e limitadas e não mostraram nenhum sinal de desestabilização dos regimes em que ocorreram. Isto posto, conseguimos enquadrar com precisão o enigma central da pesquisa sobre legitimidade: quais são e onde estão os efeitos ausentes do declínio observado da legitimidade? Se a legitimidade de fato diminuiu muito, por que não tem havido protestos mais freqüentes e disseminados contra as democracias estabelecidas?

Para resgatar a teoria da legitimidade desse embaraço, pode-se voltar à noção de Easton e Lipset de um "reservatório" de apoio, construído ao longo dos anos e, portanto, de erosão lenta. Porém, essa explicação parece sem valor diante de vários fatos. Embora os escores da legitimidade estejam baixos nos Estados Unidos (depois de uma efêmera recuperação pós-11 de setembro), a eleição de 2004 teve um forte aumento do comparecimento dos eleitores e uma nova participação de cidadãos no financiamento das campanhas através da internet. Até mesmo em países de democratização recente, que deveriam ter poucas reservas de legitimidade para atravessar tempos difíceis, os regimes democráticos parecem suportar as crises violentas, como demonstra tão bem o caso da Argentina em anos recentes ${ }^{5}$.

Tudo isso sugere uma disjunção aguda entre o que a teoria da legitimidade prediz e o que está acontecendo na realidade. O que, então, está errado? A teoria é falha e a legitimidade política irrelevante para a estabilidade política, ou mesmo para o protesto? Ou há algo de errado com o modo como conceituamos e medimos

\footnotetext{
4 Przeworski et al. descobriram que a única variável que importa para predizer o colapso democrático é o desenvolvimento econômico: “(...) nenhuma democracia foi jamais subvertida [isto é, derrubada], não durante o período que estudamos, e nem mesmo antes ou depois, independentemente de todo o resto, em um país com uma renda per capita mais alta do que a da Argentina em 1975: US\$6.055. Não há dúvidas de que a democracia é estável em países ricos" (PRZEWORSKI et al., 2000, p. 98). Desse modo, a estabilidade dos países ricos no período posterior à Segunda Guerra Mundial pareceria completamente independente da legitimidade política (e de todas as outras atitudes políticas de massa). Manifestamos dúvidas sobre essa noção radical.

5 Estamos evidentemente conscientes de que ocorreram interrupções em países recentemente democratizados, como ilustram o golpe do governo Fujimori no Peru e o golpe de curta duração contra Chávez na Venezuela. Além disso, sabemos do grave enfraquecimento das liberdades democráticas na Venezuela, antes e especialmente depois do golpe fracassado. O colapso de muitas democracias européias no entre-guerras também está bem documentado. Mas nosso argumento é que os colapsos democráticos são bastante raros em sociedades industriais estabelecidas e exceções em nações em processo de democratização, mesmo entre países nos quais as pesquisas de opinião mostram forte e demorada desilusão pública.
} 
legitimidade, de tal maneira que a pesquisa empírica pode não estar examinando as variáveis corretas? Este artigo explora a segunda questão, porque se não formos capazes de ser mais precisos e confiantes em nossa medida do conceito de legitimidade, não poderemos testar realmente a teoria. Com medições melhores e com os contornos da legitimidade mais bem conhecidos, talvez possamos concluir que a teoria funciona e, possivelmente, que os resultados contraditórios no mundo real discutidos acima são adequados à teoria. Ou então, se mesmo amplos esforços para melhorar a medição não produzirem melhores previsões no mundo real, pode ter chegado o momento de reavaliar a utilidade da teoria. Este artigo oferece um exame detalhado da medida e da dimensionalidade da legitimidade política em públicos de massa. Empregamos um conjunto de dados especialmente relevantes coletados na Costa Rica, uma democracia muito estável em um país em desenvolvimento.

A legitimidade (concebida amplamente como apoio dos cidadãos ao governo) é um conceito teoricamente rico, mas acreditamos que tem sido mal definido e mal verificado empiricamente. Assim, apesar das contribuições teóricas fundamentais de David Easton (1965 e 1975), a validade do constructo da legitimidade foi pouco verificada ${ }^{6}$. Desse modo, para um conceito de uso tão disseminado, pouco foi definitivamente estabelecido sobre a estrutura da legitimidade ou seus efeitos sobre a estabilidade política. Supôs-se, mas nunca se demonstrou, que o apoio dos cidadãos ao regime influi de alguma forma nas chances de sobrevivência desse regime. Afirmou-se, por exemplo, que a República de Weimar caiu e Hitler foi eleito devido à falta de legitimidade do regime. Contudo, a ausência de dados de surveys na Alemanha nos anos 1920 e 1930 deixa a afirmação sem teste. Com efeito, os observadores atribuem o colapso generalizado das democracias européias antes da Segunda Guerra Mundial a problemas de legitimidade, mas nenhuma pesquisa empírica sustenta essa afirmação (BERMEO, 2003). A determinação dos efeitos do declínio da legitimidade poderia ser particularmente importante para as novas democracias, porque poderíamos supor que até uma perda relativamente pequena de apoio ao sistema poderia destruir suas frágeis instituições democráticas e a própria democracia. Neste artigo, examinamos primeiramente a literatura sobre legitimidade e a noção relacionada de "apoio político" e depois exploramos empiricamente o conceito, na esperança de esclarecê-lo.

\footnotetext{
${ }^{6}$ A validade do constructo refere-se a se uma variável (ou, no nosso caso, um grupo de variáveis relacionadas) é internamente coerente (validade interna) e mede o que pretende medir no mundo empírico (validade externa).
} 


\section{Pesquisas anteriores sobre legitimidade: especificação e desagregação}

Quase toda a pesquisa empírica nesse campo decorre da teoria pioneira de David Easton, que fundamentou a definição de legitimidade política dentro do quadro do que chamou de "apoio político". A concepção de Easton tem a grande vantagem de subdividir o conceito de legitimidade política em certos componentes que são mais generalizados (relacionados com valores mais básicos e fundamentais) e outros que estão relacionados com fenômenos mais específicos (avaliação de líderes bem conhecidos e de instituições específicas do governo). Easton perguntou: "É possível fazer uma distinção válida entre apoio específico e difuso? O apoio em ambos esses modos deve ser construído como uni ou multidimensional?" (EASTON, 1975, p. 435). Seu argumento a favor da multidimensionalidade continua a dar forma à discussão e à pesquisa sobre essa questão.

Easton definiu legitimidade em termos de atitudes dos cidadãos, especificamente "a convicção 'de que é certo e apropriado (...) obedecer às autoridades e sujeitar-se às exigências do regime'” (EASTON, 1975, p. 451). Ele identificou duas dimensões principais de apoio político conforme seus objetos apoio difuso (que foi depois dividido em atitudes em relação à comunidade política e aquelas voltadas para o regime) e apoio específico (orientado para o desempenho das autoridades políticas, isto é, dos ocupantes do poder) ${ }^{7}$. As avaliações dos cidadãos do desempenho e dos atos das autoridades e seus conseqüentes benefícios/custos determinariam os níveis de apoio específico. Experiência pessoal, ideologia e socialização moldariam o apoio difuso.

A teorização mais recente sobre legitimidade política começa com uma discussão de Nye e Zelikow (1997, p. 278) e tem seguimento com Norris (1999) e Dalton (1999 e 2004), que refinam a conceituação de legitimidade de Easton e aprofundam a explicação de sua dimensionalidade. Norris teoriza que a legitimidade política (na orientação dos cidadãos) tem cinco componentes baseados em opinião favorável ou crítica de certos objetos, e cada um define uma dimensão: são eles a comunidade política (a nação), os princípios do regime (valores centrais do sistema político), o desempenho do regime (o funcionamento do regime na prática), as instituições do regime (as instituições existentes de governo) e os atores políticos (líderes no poder) (NORRIS, 1999, p. 11-12). Na esteira de Easton, alguns destes vão do geral ao específico. As discussões de Easton, Norris e Dalton nos

\footnotetext{
7 Easton (1965) trabalhou estas noções em um nível mais teórico em obras anteriores. Isso levou vários estudiosos a sugerir que Easton tinha uma noção tridimensional em mente (comunidade política, regime e autoridades). Essa é a noção que Dalton (2004, p. 5) utiliza, e nossa representação da tese em duas dimensões, em que comunidade política e regime são subdimensões de "apoio difuso" não contradiz tal leitura, mas apenas vê as duas primeiras dimensões como distintas da terceira.
} 
levam a esperar múltiplas dimensões e subdimensões da legitimidade, baseadas em objetos políticos particulares. Por implicação, os cidadãos podem dar individualmente mais ou menos apoio em cada dimensão e diferentes países teriam contornos variados de legitimidade baseados nas posições médias de seus cidadãos nas dimensões.

Na esfera do empírico, a pesquisa sobre legitimidade baseou-se de início em larga medida em um conjunto de itens sobre "confiança no governo" desenvolvido pelo Survey Research Center da Universidade de Michigan. Perguntavam, por exemplo, "o quanto do tempo você pensa que pode confiar no governo de Washington para fazer o que é certo"8. Os esforços para verificar empiricamente a multidimensionalidade da legitimidade estavam muito atrasados em relação à teorização de Easton, mas acabaram por progredir através de dois estágios. Lowenberg (1971) começou um debate argumentando que a distinção de Easton entre apoio específico e difuso não era empiricamente verificável. A ampla discussão de Rogowski (1974) sobre a teoria da legitimidade levantou questões básicas sobre a dicotomia entre os dois tipos de apoio. Em um debate agora clássico, Miller (1974) sustentou que os declínios observados na série "confiança no governo" de Michigan revelavam o crescimento da alienação política nos Estados Unidos, enquanto que Citrin (1974) contra-argumentava que a medida de confiança avaliava apenas o descontentamento superficial com as autoridades eleitas da época. Esse debate provocou uma série de artigos que levantaram sérios questionamentos em relação à confiabilidade e validade dos itens sobre confiança no governo e ofereceram a primeira verificação empírica das dimensões de apoio difuso e específico (MULLER, JUKAM e SELIGSON, 1982; CITRIN e MUSTE, 1999).

Apesar desse início promissor e do amplo reconhecimento da importância de desagregar legitimidade/apoio, boa parte das pesquisas nos anos seguintes se concentrou em apenas uma dimensão. Por exemplo, após uma extensa discussão da dimensionalidade do apoio, Fuchs, Guidorossi e Svensson (1995, p. 325-29) empregaram uma única variável (satisfação com a democracia) em sua análise do apoio nas democracias européias.

Nessa segunda fase, a pesquisa ultrapassou a noção bidimensional difuso/específico para uma conceituação multidimensional mais ampla da legitimidade política. Kornberg e Clarke (1992), usando dados de um survey realizado no Canadá, examinaram três "objetos de apoio": comunidade, regime e autoridades. Esta análise descreveu (mas não apresentou) um modelo unidimensional consistente com a tese de que as dimensões de apoio não são empiricamente distinguíveis. Os autores concluíram que "esse modelo tem um ajuste totalmente insatisfatório" (KORNBERG e CLARKE, 1992, p. 114) e depois

\footnotetext{
8 Para o conjunto completo de itens ver Citrin e Muste (1999, p. 481-83).
} 
apresentaram uma análise fatorial confirmatória na qual as dimensões para comunidade, regime e autoridades separavam-se de forma clara. Isso dava suporte à validade empírica da multidimensionalidade da legitimidade, mas não era definitivo porque um único item (uma única questão do survey) era usado para medir cada dimensão.

A contribuição empírica de Kornberg e Clarke sobre a multidimensionalidade influenciou a teorização de Nye e Zelikow (1997) e Norris (1999) em publicações importantes, mas outros esforços empíricos para verificar a multidimensionalidade da legitimidade e explorar seus contornos em diferentes nações continuaram limitados. Norris (1999, p. 16-21) discutiu em detalhe as perguntas que poderiam explorar a estrutura dimensional que ela propôs, mas não analisou empiricamente os itens selecionados. Klingemann (1999) fez análise fatorial de uma série de itens tirados dos World Values Surveys de meados da década de 1990 em 39 países. Porém, em vez tentar detectar todas as cinco dimensões propostas por Norris, ele procurou e encontrou três através dos países - apoio à comunidade política, aos princípios do regime e ao desempenho do regime - e relatou variação em nível nacional nessas dimensões. Klingemann não examinou duas das dimensões de Norris (apoio a instituições do regime e a atores políticos), e explicou o porquê: "Os analistas encontram problemas de análise secundária. Eles são obrigados a usar aqueles indicadores que finalmente entraram no questionário, embora alternativas pudessem ter sido preferidas" (KLINGEMANN, 1999, p. 35). Klingemann também relatou problemas com algumas das dimensões hipotéticas. Por exemplo, as correlações entre alguns itens que supostamente definiam dimensões eram baixas, especialmente aquelas para comunidade política (1999, p. 38, n. 9). Além disso, a análise fatorial de Klingemann examinou a amostra reunida de 38 países, não deixando claro se a estrutura dimensional encontrada fora confirmada para cada país em separado. Uma vez que sua análise posterior foi no nível de país (por exemplo, demonstrando países com apoio maior ou menor para a comunidade política), essas estimativas pontuais talvez não tenham refletido a mesma estrutura dimensional para cada país da amostra.

Dalton (1999), usando uma definição de cinco dimensões paralela à de Norris, utilizou uma série de estudos eleitorais nacionais de democracias industriais avançadas para buscar provas da evolução das dimensões de legitimidade ao longo do tempo. Contudo, esse estudo não tentou confirmar empiricamente a dimensionalidade real das questões usadas para captar a suposta estrutura de apoio de cinco dimensões que serve de base para o trabalho.

O esforço mais ambicioso que encontramos até agora é a recente análise de Dalton de oito nações industriais avançadas tirada da série 1995-1998 dos World Values (DALTON, 2004, p. 57-62). Usando análise fatorial em uma amostra reunida (multinacional), ele revelou quatro dimensões de legitimidade: apoio à comunidade, 
à democracia, a instituições e a autoridades. No entanto, esse esquema omitiu a categoria de "desempenho do regime" que Norris (1999) e Dalton (1999, p. 68-69) haviam proposto e que Dalton havia analisado em trabalho anterior. Ademais, a dimensão teorizada de "apoio aos princípios do regime" foi transformada na medida muito mais estreita de "apoio à democracia". Além disso, e de modo muito mais problemático, Dalton (tal como Klingemann antes dele) usou uma análise fatorial com rotação varimax (que pressupõe ortogonalidade ou correlação zero entre dimensões). Porém, a teoria que estava sendo testada supõe explicitamente que várias dimensões de apoio estariam mutuamente relacionadas (isto é, pressupõe dimensões inter-correlacionadas, em vez de não-correlacionadas). Para remediar esse problema, Dalton (2004, p. 60 n. 4) mencionou em nota uma análise fatorial oblíqua, mas não apresentou os resultados e, então, não sabemos como se comparam as soluções ortogonal e oblíqua. As medidas usadas na solução quadridimensional usada em todo o livro empregaram os escores da análise fatorial com rotação varimax. Em conseqüência, os escores de legitimidade ortogonais (isto é, não-correlacionados) foram usados para a análise, apesar de ele ter confirmado o que a teoria da legitimidade afirma - que as dimensões estão, de fato, correlacionadas.

\section{Os desafios da pesquisa}

Baseados na revisão da literatura descrita acima, encontramos seis desafios à validação do constructo da legitimidade. O primeiro, podemos chamar de "a armadilha comparativa", vemos em alguns estudos empíricos recentes sobre a legitimidade que empregam bases de dados multinacionais e análises comparativas $^{9}$. O problema surge do fato de que boa parte da legitimidade que foi medida per se está orientada para determinados sistemas políticos do mundo real e o desempenho de suas instituições e seus atores. Em amostras comparativas de vários países, cada cidadão que avalia o desempenho dos atores políticos, por exemplo, está reagindo aos problemas da comunidade, regime, governo ou desempenho de sua própria nação ${ }^{10}$. Esses pontos de referência variam de país para país dentro das amostras, de tal modo que há, com efeito, um problema de heterocedasticidade em bases de dados comparativas (SELIGSON, 2002a). Assim, em nossa opinião, a dimensionalidade e os contornos da legitimidade deveriam ser primeiramente estabelecidos em nações isoladas e depois se fariam as

\footnotetext{
9 Exceções são Preston, Briggs, Kornberg, e Clarke (1983) e Kornberg e Clarke (1992).

10 Para um argumento semelhante relacionado à participação política, ver Norris (2002, p. xi-xiv).
} 
comparações entre os $\operatorname{casos}^{11}$. Não fazemos essa observação para rejeitar a pesquisa comparativa, uma vez que esta deve ser nosso objetivo último. Mas acreditamos que os estudiosos devem primeiro empreender esforços cuidadosos para estabelecer a dimensionalidade da legitimidade em nível nacional, a fim de confirmar plenamente que os constructos de legitimidade previstos existem de fato e fazem sentido em casos particulares.

Em segundo lugar, boa parte dos trabalhos clássicos sobre legitimidade baseia-se na análise fatorial como principal ferramenta metodológica para estabelecer a dimensionalidade do conceito. Porém, uma vez que as dimensões da legitimidade estão inerentemente relacionadas umas com as outras, as soluções usuais de rotação varimax contradizem o argumento teórico básico. O trabalho empírico (KORNBERG e CLARKE, 1992; CANACHE, 2002) confirma que as dimensões estão, de fato, inter-relacionadas. Uma solução parcial é usar uma rotação oblíqua na análise fatorial, mas como já observamos neste artigo, avanços na modelagem de equações estruturais, especialmente no que tange à análise fatorial confirmatória (AFC), nos permitem superar várias limitações da análise fatorial e obter uma imagem mais clara das dimensões latentes que extraímos dos dados, sua força e suas inter-relações.

O terceiro obstáculo deriva do alto custo dos surveys. Nas pesquisas de opinião pública, é geralmente preferível que o pesquisador use várias questões relacionadas para confirmar a validade do constructo de um conceito como o de confiança interpessoal ou legitimidade. Porém, empregar múltiplos itens para representar cada dimensão da legitimidade é caro, e assim o trabalho empírico sobre legitimidade e outras dimensões da opinião baseia-se, com freqüência, em um pequeno número de itens - e, às vezes, em uma única pergunta, como observamos na revisão dos trabalhos anteriores. Essa limitação afeta especialmente grandes projetos de pesquisa nacionais e comparativos mas afeta também estudos de caso sobre apoio político em determinadas democracias (FUCHS, 1999; HOLMBERG, 1999; ROSE, SHIN e MUNRO, 1999). Portanto, explorar de modo mais adequado a estrutura real das dimensões da legitimidade exigiria, idealmente, múltiplos itens de surveys relacionados a cada objeto que se acredita definir uma dimensão (DALTON, 2004).

Em quarto lugar, ao fazer a revisão da literatura sobre legitimidade/apoio, fomos surpreendidos pela escassez de pesquisas sobre esse tema em nível local. Uma vez que muitas pesquisas mostraram que os cidadãos interagem mais com as

\footnotetext{
11 O problema é parecido com o estabelecimento da dimensionalidade da participação política tal como examinado por Verba e Nie (1972), que exploraram esse problema tanto no contexto dos Estados Unidos e comparativamente (VERBA, NIE e KIM, 1971). Eles descobriram que a dimensionalidade da participação é universal, mas que a particularidade de sua estrutura é definida pelo contexto institucional nacional.
} 
instâncias governamentais que Ihe são mais próximas, ficamos realmente surpresos com o fato de os pesquisadores ignorarem a legitimidade do governo local. Essa lacuna é especialmente problemática no mundo em desenvolvimento, no qual a descentralização se tornou um mantra para muitos programas de reforma estrutural promovidos pelas agências de desenvolvimento que buscam "devolver o governo ao povo" (VELIZ, 1980; NICKSON, 1995; CROOK e MANOR, 1998; DIAMOND, 1999). Além disso, surgem indícios de que o governo local propicia um foro de participação alternativo à política em nível nacional (BOOTH e RICHARD, 1996) e que o apoio dos cidadãos ao governo local conduz ao engajamento no nível local (BOOTH e SELIGSON, no prelo). Isso sugere o começo de uma explicação de porque o declínio da legitimidade nacional não levou a mais crises de regimes: que os cidadãos críticos podem estar se voltando para arenas e modos de participação alternativos, em vez de se retirarem, protestarem ou desafiarem os governo nacionais. Testamos vários itens relacionados com o apoio ao governo local.

Em quinto lugar, é preciso pensar melhor sobre a dimensão de "apoio aos princípios do regime", que Dalton define como "os amplos parâmetros dentro dos quais o sistema político deveria funcionar" (DALTON, 2004, p. 6). No entanto, Norris argumenta que "(...) uma vez que a democracia continua a ser um conceito essencialmente questionado, aberto a múltiplos significados, não há consenso sobre quais valores deveriam ser considerados mais importantes" (NORRIS, 1999, p. 11). Concordamos com Norris nesse ponto, mas a solução dela, e de quase todos os outros pesquisadores, foi usar os itens dos questionários que se referem diretamente a "democracia". Vemos dois problemas quando a palavra "democracia" é incluída em questões que tentam medir princípios do regime. Primeiro, há o problema do viés pela resposta de "desejabilidade" social (KROSNICK, 1999, p. 44-49), que pode tornar difícil para os respondentes expressar apoio público à ditadura, contra uma percepção de maior "desejabilidade" social para a democracia. Em segundo lugar, os surveys mostraram que determinados públicos podem ter interpretações muito diferentes do termo. Por exemplo, um estudo relevante para nosso tema concluiu que a maioria dos costarriquenhos definia democracia em termos de liberdade, enquanto os chilenos a viam em termos de capitalismo e livre empresa/livre comércio (SELIGSON, 2001). Contudo, apesar desses problemas, Norris (1999, p. 16-17), Dalton (2004, p. 58-59) e Klingemann (1999, p. 36-38) confiaram em itens que perguntavam sobre a aprovação da "democracia como a melhor forma de governo" e uma preferência pela "democracia" em relação à "ditadura". Acreditamos que essa abordagem na operacionalização dos princípios do regime sofre tanto de viés de resposta como de confusão conceitual potencial pelo respondente.

A discrepância na interpretação da democracia entre os respondentes e o potencial de viés na resposta sugere que os pesquisadores deveriam evitar o termo democracia per se e, ao invés, perguntar sobre os princípios essenciais que aqueles 
que apóiam a democracia deveriam ter. Um traço essencial da democracia - na verdade, o cerne de sua definição central - é a participação dos cidadãos na política (COHEN, 1973; PATEMAN, 1970). Nossa preferência e nossa estratégia adiante é substituir as questões sobre princípios do regime que mencionam democracia por outras que enfocam o grau em que os cidadãos aprovam a participação política, que está no coração conceitual da democracia.

Uma sexta e última dificuldade que encontramos nas pesquisas anteriores é a maneira como a dimensão de "desempenho do regime" foi operacionalizada. Tal como em nossa preocupação com a medição dos princípios do regime, cremos que não ajuda usar itens que incluam o termo "democracia". Um trabalho anterior mostrou que itens que medem satisfação com a democracia (CANACHE, MONDAK e SELIGSON, 2001) confundem, na verdade, satisfação com o desempenho do regime e satisfação com a democracia como sistema de governo. Embora nem todos concordem com nossa preocupação (ANDERSON e GUILLORY, 1997), cremos que não há razão para fundir os dois conceitos, ainda que os itens usados para medir satisfação com o desempenho do regime sejam sugeridos por Norris (1999, p. 18).

Klingemann (1999, p. 36-37) emprega os itens de desempenho do regime de Norris, mas acrescenta outros que julgamos mais apropriados. Ele usa questões que investigam claramente o desempenho do regime ao perguntar "como vão as coisas" e "quão satisfeito você está com o modo como as pessoas que estão no governo nacional cuidam dos negócios do país". Infelizmente, ele inclui também itens que medem a confiança em instituições específicas (nesse caso, o Parlamento e o Governo Central), que se sobrepõem conceitualmente e confundem as importantes distinções feitas por Norris entre apoio aos princípios do regime e apoio às instituições do regime. Desse modo, a análise dimensional de Klingemann elimina inteiramente as instituições.

Dalton (2004, p. 59), ao contrário, tem um esquema em que o apoio às instituições do regime surge como uma dimensão separada, mas ele não encontra uma dimensão que meça o desempenho do regime. Mishler e Rose (1999) usam um outro mecanismo para medir o desempenho do regime, com o qual comparam os regimes atuais da Europa Oriental com seus predecessores comunistas. Consideramos isso uma excelente maneira de medir o desempenho do regime em países pós-comunistas, mas menos útil em países em que o regime não sofreu mudanças drásticas. Assim, é preciso utilizar outras medidas e, para tanto, propomos questões amplamente usadas e testadas sobre desempenho do regime os itens sociotrópicos padrão sobre o desempenho da economia. Embora sejam limitados à esfera econômica, esses itens são usados em tantos surveys e o desempenho da economia é um fator tão crítico na avaliação que os cidadãos fazem do governo que achamos que seu uso se justifica amplamente. 
Em suma, acreditamos que persiste a necessidade de explorar a dimensionalidade da legitimidade e a validade do constructo usando metodologia apropriada, evitando ao mesmo tempo os seis problemas acima mencionados. Ou seja, nesse estágio de nossa preocupação com a incapacidade das previsões da teoria da legitimidade de corresponder à realidade, é preciso empreender pesquisas em nível nacional. Devemos utilizar múltiplos itens para cada uma das possíveis dimensões da legitimidade a fim de aumentar a chance de estabelecer a validade da dimensionalidade e as possíveis relações entre as dimensões. Acreditamos que oferecemos aqui uma contribuição útil nesse sentido. Examinamos a legitimidade em um determinado contexto nacional - a Costa Rica - com um survey expressamente projetado para incluir a potencial multiplicidade de itens representativos dos objetos de legitimidade. Exploramos a dimensionalidade da legitimidade usando análise fatorial confirmatória.

Somente depois de estabelecer a validade do constructo da legitimidade em pelo menos alguns países é que poderemos explorar com proveito suas fontes e seus efeitos. Uma vez validado em casos nacionais individuais, poderemos avançar para a análise comparativa e para uma exploração útil dos modos como os componentes da legitimidade podem ou não estar conectados com o comportamento dos cidadãos no mundo real e, em última análise, com a estabilidade dos regimes.

\section{0 cenário}

A Costa Rica oferece um excelente caso para examinar a estrutura da legitimidade democrática. É a democracia mais antiga e mais estável da América Latina. Goza de um período contínuo de probidade eleitoral e governo civil desde o estabelecimento do regime atual, no final da década de 1940. Nos anos 1990, o país já evoluíra para um sistema bipartidário dominado pelo social-democrata Partido de Libertação Nacional (PLN), fundado no começo dos anos 1950, e o Partido da Unidade Social Cristã (PUSC), que surgiu de uma coalizão de partidos conservadores na década de 1980. Apesar do histórico impecável de eleições limpas e da estabilidade do regime por cinco décadas, a Costa Rica experimentou um inesperado declínio de comparecimento eleitoral nas duas últimas eleições nacionais. Além disso, deserções do PLN e uma forte votação em um novo partido insurgente forçaram pela primeira vez a realização de um segundo turno nas eleições presidenciais de 2002. Esses eventos e tendências sugeriram a muitos observadores um possível problema de queda da legitimidade ou, pelo menos, de declínio da legitimidade do sistema partidário, e um forte aumento na quantidade de cidadãos críticos na Costa Rica (BOOTH, no prelo). Em 2004, depois da coleta dos dados aqui analisados, uma série de graves escândalos envolvendo dois expresidentes sacudiu o país e levantou mais questões sobre a estabilidade do 
sistema partidário existente. Por fim, a economia do país enfrentou dificuldades muito significativas em décadas recentes, piorando a distribuição de renda, alterando a estrutura e a cobertura dos serviços públicos e forçando a adoção de um novo modelo econômico, neoliberal (BOOTH, 1998; WILSON, 1998; CLARK, 2001; ROVIRA MAS, 2001). Essas mudanças sugerem a possibilidade de reações bastante divergentes aos contextos econômico e político entre os cidadãos as quais deveriam nos permitir identificar insatisfação com diferentes objetos políticos, do mais abstrato (o sistema democrático) ao mais concreto (políticos no poder).

Conseguimos explorar a estrutura e os determinantes da legitimidade na Costa Rica contemporânea em um grau de detalhamento até então não conseguido em outros lugares, inclusive na própria Costa Rica. No final de 2002, coletamos entrevistas em uma amostra nacional de 1.016 cidadãos costarriquenhos em idade de votar. O survey incluiu várias dezenas de perguntas deliberadamente estruturadas para permitir o teste da proposta de legitimidade de Easton, tal como expandida por Norris e Dalton. Há múltiplos itens para cada objeto de avaliação, bem como muitos mais itens para medir o apoio dos cidadãos a outras instituições, inclusive o governo local, que foi omitido no esquema Easton/Norris/Dalton.

O conjunto de dados - Os dados para esta análise foram retirados de uma amostra probabilística nacional projetada por Miguel Gómez B. A amostra é representativa da população de 18.69 anos de idade e foi desenhada como estratificada em múltiplos estágios, com cluster e probabilidade proporcional ao tamanho (PPT). Especificamente, o país foi dividido em cinco estratos geográficos: a área da grande San José metropolitana, outras áreas urbanas do Vale Central, áreas rurais do Vale Central, o resto das áreas urbanas e o resto das áreas rurais. A amostra metropolitana foi estratificada ainda em três zonas socioeconômicas: alta, média e baixa.

Em cada estrato, houve um processo de seleção em dois estágios. 0 primeiro estágio consistiu na seleção de segmentos do censo nacional de 2000 , usando técnicas de PPT, e dentro de cada segmento, foi designado um cluster de oito domicílios ${ }^{12}$. O segundo estágio, no domicílio, seguiu os procedimentos amostrais sugeridos por Sudman (1966). A amostra resultante totalizou 1.016 casos e foi ponderada para refletir a distribuição real da população, tal como refletida no censo de 2000 .

\footnotetext{
12 Informações preliminares do censo foram postas a nossa disposição em junho de 2002 pelo Instituto Nacional de Estatística e Censos da Costa Rica.
} 


\section{Medida: o desafio da seleção de variáveis}

O desafio imediato no estudo da estrutura da legitimidade, como observamos acima, é a determinação das questões que se pode razoavelmente supor que medem seus vários componentes ou dimensões. Nessa fase da pesquisa, o trabalho de Norris (1999, p. 9-21) nos ajudou muito ao conceituar com clareza as dimensões da legitimidade e vinculá-las a questões usadas em muitos dos grandes surveys multinacionais. Começamos, então, com os itens desenvolvidos especificamente para o esquema de Norris, incluídos em seu estudo comparativo baseado no World Values Survey e no Eurobarometer. Mas a lista de Norris não era inclusiva e, então, acrescentamos outros itens usados comumente para medir apoio político em outros estudos, com um grande número de referentes institucionais e de atores (FINKEL, MULLER e SELIGSON, 1989; MULLER, JUKAM e SELIGSON, 1982; MULLER e WILLIAMS, 1980; SELIGSON, 2002a). Incluímos medidas de apoio a atores políticos e suas políticas, em específico, o presidente da Costa Rica.

Como observamos na revisão da literatura, acreditamos que mensurar o apoio aos princípios básicos do regime com base na aprovação da "democracia" emprega uma estratégia de medição inapropriada ao incluir nas perguntas essa palavra tão sobrecarregada. Em vez disso, voltamos nosso foco para a norma fundamental da participação política, a essência da democracia. Portanto, para medir o apoio aos princípios do regime, empregamos uma série de questões que medem a aprovação da participação política. Em nossas tentativas iniciais de estudar a dimensionalidade da legitimidade, usamos itens idênticos aos de Norris, mas concluímos que eles se relacionavam mal uns com os outros e muito pouco com outras dimensões da legitimidade. Porém, nossa decisão de rejeitar aqueles itens veio da preocupação mais profunda com a "desejabilidade" social e com a confusão conceitual. Do mesmo modo, preocupamo-nos com outra possível confusão conceitual entre apoio ao desempenho do regime e apoio às instituições do regime. Assim, usamos uma bateria de três itens sociotrópicos padrão relacionados ao desempenho da economia nacional. Por fim, acrescentamos novos itens, especialmente uma série relacionada com o apoio ao governo local como objeto de referência (SELIGSON, 2002c; SELIGSON, GRIJALVA e CÓRDOVA, 2002).

A Tabela 1 lista os itens que utilizamos, agrupados por dimensão da legitimidade prevista, seguindo o esquema estabelecido por Norris (1999, p. 10). Também emendamos o agrupamento para incluir a orientação em relação ao governo local, um objeto que acrescentamos baseados no raciocínio desenvolvido acima, bem como em nossa conceituação alternativa dos princípios do regime e do desempenho do regime. Observe-se que, com o objetivo de reduzir os efeitos de unidade e medição de grupos de itens similarmente estruturados em análises estatísticas subseqüentes, recodificamos todos os itens da Tabela 1 para ter uma amplitude de 0 a 100. 
Tabela 1

Dimensões da legitimidade política baseadas em Norris

\begin{tabular}{|c|c|c|c|}
\hline $\begin{array}{c}\text { Objeto de apoio } \\
\text { (listados do mais geral } \\
\text { ao mais específico) }\end{array}$ & Operacionalização da variável & Média & $\begin{array}{l}\text { Desvio } \\
\text { padrão }\end{array}$ \\
\hline $\begin{array}{l}\text { Existência de uma } \\
\text { comunidade política }\end{array}$ & $\begin{array}{l}\text { 1. Em que medida você sente orgulho de ser } \\
\text { costarriquenho? (escala de } 7 \text { pontos: recodificada em } \\
\text { "muito" }=100 \ldots \text {... "nada" }=0 \text { ). } \\
\text { 2. Em que medida você concorda que, apesar de nossas } \\
\text { diferenças, nós costarriquenhos temos muitas coisas e } \\
\text { valores que nos unem como país? (escala de } 7 \text { pontos: } \\
\text { recodificada em "concorda muito" = } 100 \ldots \text { ".. discorda } \\
\text { muito" = 0). } \\
\text { Média do grupo }\end{array}$ & 96,75 & 12,97 \\
\hline $\begin{array}{l}\text { Apoio aos princípios } \\
\text { centrais do regime }\end{array}$ & $\begin{array}{l}\text { Vou ler para você uma lista de algumas ações ou coisas } \\
\text { que as pessoas podem fazer para alcançar suas metas } \\
\text { e objetivos políticos. Por favor, me diga em que medida } \\
\text { você aprova ou desaprova as pessoas que fazem estas } \\
\text { coisas: (escala de } 10 \text { pontos: } 0=\text { "desaprova muito"; } 10 \\
=\text { "aprova muito", transformada em uma escala de } 0 \text { - } \\
\text { 100). } \\
1 \text {. Que as pessoas participem de manifestações } \\
\text { legalmente permitidas. } \\
\text { 2. Que as pessoas participem de um grupo que tenta } \\
\text { resolver os problemas da comunidade. } \\
\text { 3. Que as pessoas trabalhem em uma campanha } \\
\text { eleitoral para um partido ou candidato. } \\
\text { Média do grupo }\end{array}$ & $\begin{array}{r}73,29 \\
86,32 \\
78,58 \\
79,35\end{array}$ & $\begin{array}{l}30,22 \\
21,98 \\
26,56 \\
21,78\end{array}$ \\
\hline $\begin{array}{l}\text { Desempenho do } \\
\text { regime }\end{array}$ & $\begin{array}{l}\text { 1. Como você classificaria, em geral, a situação } \\
\text { econômica do país? (escala de } 5 \text { pontos: recodificada } \\
\text { em "muito boa" }=100 \ldots \text { ".. "muito ruim" }=0 \text { ) } \\
\text { 2. Você acha que a situação econômica do país está } \\
\text { melhor, mais ou menos a mesma ou pior do que há um } \\
\text { ano? (escala de } 5 \text { pontos: recodificada em "muito } \\
\text { melhor" = } 100 \ldots \text {... "muito pior" }=0 \text { ) } \\
\text { 3. Você acha que nos próximos } 12 \text { meses a situação } \\
\text { econômica do país ficará melhor, a mesma ou pior do } \\
\text { que agora? (escala de } 5 \text { pontos: recodificada em "muito } \\
\text { melhor" = } 100 \text {... "muito pior" }=0 \text { ) } \\
\text { Média do grupo }\end{array}$ & 41,00 & 19,06 \\
\hline
\end{tabular}




\begin{tabular}{|c|c|c|c|}
\hline $\begin{array}{c}\text { Objeto de apoio } \\
\text { (listados do mais geral } \\
\text { ao mais específico) }\end{array}$ & Operacionalização da variável & Média & $\begin{array}{l}\text { Desvio } \\
\text { padrão }\end{array}$ \\
\hline $\begin{array}{l}\text { Instituições do regime } \\
\text { (apoio difuso) }\end{array}$ & $\begin{array}{l}\text { Todos os seguintes itens estão em uma escala de } 7 \\
\text { pontos: } 0 \text { = "nada" ... } 7 \text { = "muito", transformada em 0- } \\
\text { 100): } \\
\text { 1. Quanto você acha que os tribunais da Costa Rica } \\
\text { garantem um julgamento justo? } \\
\text { 2. Quanto você respeita as instituições políticas da Costa } \\
\text { Rica? } \\
\text { 3. Quanto você acha que os direitos básicos dos cidadãos } \\
\text { são bem protegidos no sistema político costarriquenho? } \\
\text { 4. Quão orgulhoso você se sente de viver no sistema } \\
\text { político costarriquenho? } \\
\text { 5. Quanto você acha que uma pessoa deve apoiar o } \\
\text { sistema político costarriquenho? } \\
\text { Média do grupo }\end{array}$ & $\begin{array}{l}57,26 \\
77,65 \\
61,11 \\
75,10 \\
75,05 \\
69,23\end{array}$ & $\begin{array}{l}24,22 \\
24,62 \\
24,40 \\
23,62 \\
23,38\end{array}$ \\
\hline Instituições do regime & $\begin{array}{l}\text { 6. Quanto você confia no Supremo Tribunal Eleitoral? } \\
\text { 7. Quanto você confia na Assembléia Legislativa? } \\
\text { 8. Quanto você se sente bem representado por seus } \\
\text { deputados no legislativo provincial? } \\
\text { 9. Quanto você confia nos partidos políticos? } \\
\text { 10. Quanto você confia na Suprema Corte? } \\
\text { Média do grupo }\end{array}$ & $\begin{array}{l}76,32 \\
56,88 \\
45,28 \\
38,99 \\
60,36 \\
55,59\end{array}$ & $\begin{array}{l}24,16 \\
27,83 \\
27,87 \\
26,93 \\
25,79 \\
19,74\end{array}$ \\
\hline $\begin{array}{c}\text { Apoio ao governo } \\
\text { local }\end{array}$ & $\begin{array}{l}\text { 1. Quanta confiança você tem na prefeitura? (escala de } 7 \\
\text { pontos: } 0=\text { "nenhuma" ... } 100=\text { "muito") } \\
2 \text {. Você diria que os serviços que a prefeitura oferece às } \\
\text { pessoas de seu cantão (município) são muito bons } \\
(100) \text {, bons }(75) \text {, nem bons nem ruins }(50) \text {, ruins }(25) \text {, } \\
\text { muito ruins }(0) \text { ? } \\
\text { 3. Como você acha que eles trataram você ou seus } \\
\text { vizinhos quando vocês foram à prefeitura para tratar de } \\
\text { alguma coisa? Muito bem (100), bem (75), nem bem } \\
\text { nem mal (50), mal (25), muito mal (0). } \\
\text { 4. Você acha que o prefeito e a câmara de vereadores } \\
\text { respondem aos desejos das pessoas sempre }(100) \text {, na } \\
\text { maioria das vezes ( } 75) \text {, algumas vezes }(50) \text {, quase } \\
\text { nunca (25), nunca (0)? } \\
\text { Média do grupo }\end{array}$ & $\begin{array}{l}48,86 \\
46,66 \\
55,73 \\
34,54 \\
46,44\end{array}$ & $\begin{array}{l}26,32 \\
23,04 \\
22,69 \\
21,53 \\
23,40\end{array}$ \\
\hline $\begin{array}{l}\text { Apoio a atores ou } \\
\text { autoridades políticas }\end{array}$ & $\begin{array}{l}\text { Todos em uma escala de } 7 \text { pontos ("nada" }=0 \ldots \\
\text { "muito" = 100): Falando do governo de Miguel Angel } \\
\text { Rodríguez, quanto este governo: } \\
\text { 1. Lutou contra a pobreza? } \\
\text { 2. Promoveu o desenvolvimento econômico? } \\
\text { 3. Combateu a corrupção no governo? } \\
\text { 4. Lutou contra o crime? } \\
\text { 5. Promoveu os princípios democráticos? } \\
\text { Média do grupo }\end{array}$ & $\begin{array}{l}48,23 \\
52,14 \\
42,51 \\
46,13 \\
55,18 \\
46,69\end{array}$ & $\begin{array}{l}25,81 \\
25,46 \\
27,40 \\
27,90 \\
24,77 \\
23,15\end{array}$ \\
\hline
\end{tabular}




\section{Resultados}

Abordamos a análise dos dados em três fases para nos ajudar a classificar a lista de variáveis da Tabela 1. Primeiro, usamos análise fatorial exploratória (componentes principais, com uma rotação varimax), pois a limitada pesquisa anterior publicada havia utilizado, em larga medida, essa técnica. Os resultados nos deram uma primeira aproximação razoável, mas, como esperávamos, trouxeram uma série de problemas (ver Anexo A). Encontramos um grave problema de distribuição de cargas embora estivéssemos usando uma técnica projetada para maximizar a ortogonalidade dos itens. Em particular, observamos esse problema para as variáveis que medem comunidade política (fator 6 no Anexo A), com a segunda variável na série ("apesar de nossas diferenças, os costarriquenhos têm muito em comum"), carregando mais pesadamente o fator 4, aquele que mede apoio aos princípios centrais do regime. Encontramos um segundo problema com os itens de instituições do regime. Na verdade, houve dois problemas diferentes aqui. Primeiro, um item que media representação ("bem representado por deputados") produziu problemas extremamente graves de distribuição de cargas. Trata-se de um problema que encontramos antes com esse item, e baseados nessa experiência e nos resultados da análise fatorial, o deixamos de lado completamente. Porém, mesmo com esse item eliminado, três dos itens de instituições do regime ("respeito às instituições", "orgulho do sistema" e "deveria apoiar sistema") dividiram suas cargas entre os fatores 1 e 6 . Assim, nossa rotação varimax não pode separar com facilidade a dimensão da comunidade política da dimensão das instituições do regime. Por fim, houve também um problema de distribuição de cargas entre o item das instituições que media confiança na prefeitura com a série de governo local, uma sobreposição que é certamente compreensível.

Em seguida, passamos para uma solução mais afinada com a expectativa teórica de que os itens que medem legitimidade estariam de fato relacionados entre si e assim passamos a aplicar a mais defensável rotação oblíqua aos resultados da análise fatorial (Anexo B). Essa solução, embora mais defensável, nos deixou com muitos dos problemas da rotação varimax.

Concluímos as duas primeiras fases da análise fatorial exploratória acreditando que havíamos obtido uma boa primeira aproximação dos resultados, ainda que a capacidade da análise fatorial de retratar adequadamente as ligações entre as dimensões subjacentes da legitimidade/apoio seja limitada e não pudéssemos resolver os problemas relatados acima nas soluções de análise fatorial. Isso nos forçou a voltar às variáveis originais e levar em conta a extrema assimetria na primeira dimensão, crença na "existência de uma comunidade política" (ver Tabela 1 para médias). As médias nesses dois itens não eram apenas mais altas do que aquelas de todas as outras variáveis do estudo, mas os desvios padrão eram 
mais baixos, indicando pouca dispersão das respostas. À pergunta "em que medida você sente orgulho de ser costarriquenho?", somente $3,6 \%$ da amostra responderam no campo negativo do continuum (escores 1, 2 ou 3 na escala original de 1-7). Apenas $4,2 \%$ da amostra responderam negativamente ao segundo item, "apesar de nossas diferenças, os costarriquenhos têm muito em comum".

A distribuição do item "orgulho", mostrada na Figura 1, revela claramente que se trata de um item de valência sobre o qual há uma concordância quase universal. Perguntamo-nos se esse resultado poderia ser específico da Costa Rica, mas encontramos um padrão similar em muitos outros países no conjunto de dados do World Values 1995-97. Nesta série, fez-se aos respondentes a mesma pergunta que fizemos na Costa Rica ${ }^{13}$. A Venezuela, na época da pesquisa (1996), vivia um longo período de profunda turbulência, com um sistema partidário desacreditado e anos de queda do PIB. Não obstante, 98,6\% dos respondentes disseram que se sentiam orgulhosos de ser venezuelanos (93,7\% "muito orgulhoso" e 4,9\% "orgulhoso"). No Peru, que também sofria de graves turbulências políticas e econômicas, 94,2\% dos respondentes disseram que se sentiam orgulhosos de ser peruanos. Os valores do orgulho nacional também foram muito altos para a República Dominicana (90,2\%), Colômbia $(96,7 \%)$ e Estados Unidos (96,9\%). Esses resultados sugerem que os costarriquenhos não são excepcionais em sua reação a essa pergunta ${ }^{14}$. Contudo, nem todos os públicos de massa reagiram assim. Por exemplo, apenas $46,9 \%$ dos alemães afirmaram sentir orgulho na série do World Values de 1995-97. Assim, em alguns países, esse item poderia discriminar entre aqueles com um alto e um baixo sentimento de comunidade política, mas na Costa Rica (e em muitos outros casos), não ajuda a diferenciar os respondentes. Tendo em vista essas distribuições altamente assimétricas, decidimos que não faria sentido continuar a analisar os itens de comunidade política nesta pesquisa e os retiramos do estágio seguinte da análise.

\footnotetext{
13 O item do World Values, embora formulado de forma idêntica na questão, oferecia uma escala de respostas com apenas quatro opções que iam de "muito orgulhoso" a "nada orgulhoso" (nosso item tinha sete respostas possíveis).

${ }^{14}$ A série do World Values não contém nosso segundo item, então não podemos compará-lo.
} 
Figura 1

\section{Distribuição das respostas do item "orgulho"}

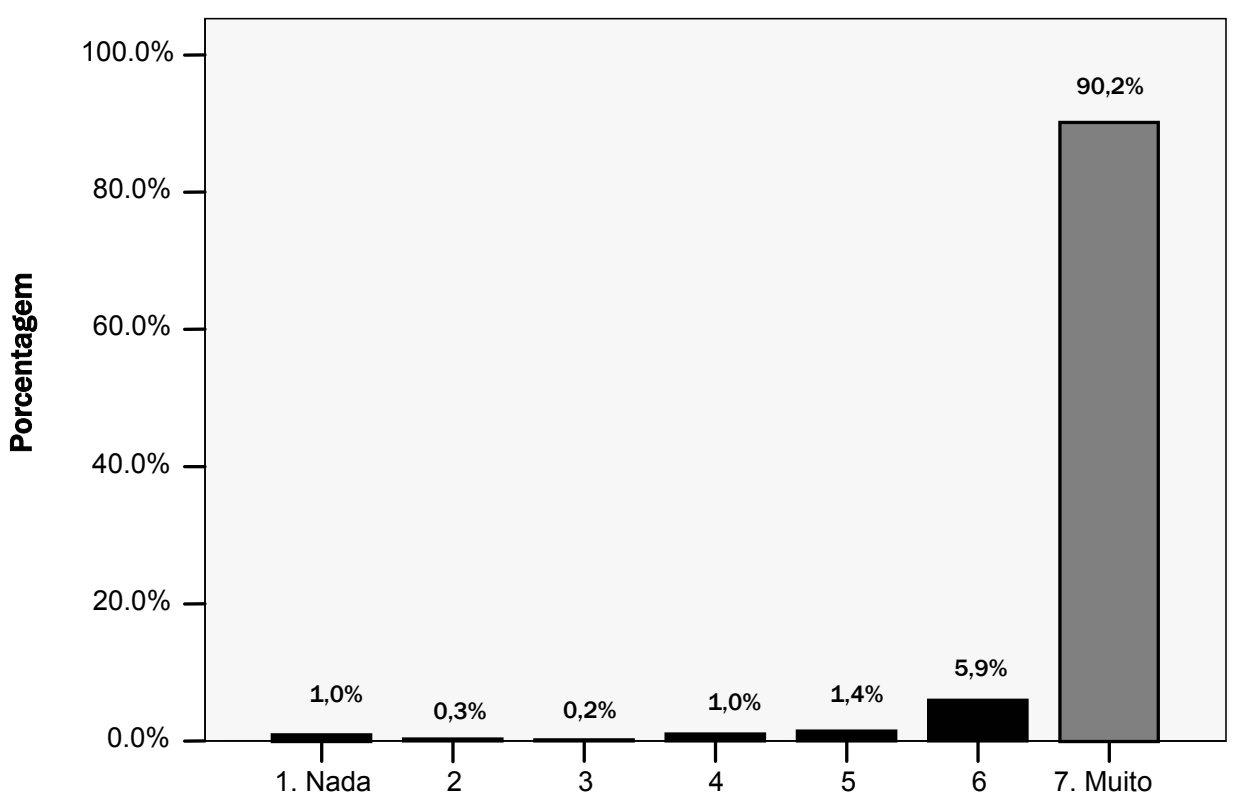

Em que medida você sente orgulho de ser costarriquenho?

Nossa análise fatorial sofreu também de um problema de dados faltantes (missing data). Decidimos, como é costume em análises desse tipo, eliminar as nãorespostas de modo pairwise. Embora sua quantidade em qualquer item não passe, em geral, de $3 \%$, em um item ("tratamento pelo governo municipal") da série do governo local, perdemos $11 \%$ dos casos. Isso significa que perderíamos $26 \%$ dos casos em uma eliminação listwise, em conseqüência do efeito composto da longa lista de variáveis que incluímos na análise.

Para enfrentar todos os problemas apontados acima, tomamos duas medidas. Primeiro, aparamos nossa lista de variáveis (deixando de lado todos os itens de comunidade política). Em segundo lugar, decidimos passar para um modelo de medição desenhado especificamente para tratar de dimensões interrelacionadas e que usa técnicas de máxima verossimilhança para atribuir valores ausentes em uma matriz. Depois submetemos a lista de variáveis encurtada a uma análise fatorial confirmatória (AFC). Esse modelo de análise ajudou-nos a identificar estruturas latentes (dimensões) entre as variáveis, ao mesmo tempo em que 
supunha que as estruturas latentes estão representadas (com erro) pelas variáveis componentes medidas. Usamos AFC por várias razões, em parte porque ela usa toda a informação do conjunto de dados por meio do emprego de estimativas de máxima verossimilhança, em vez de eliminar as não-respostas de modo pairwise. Além disso, podemos comparar múltiplos modelos em uma única análise. $\mathrm{E}$ o que talvez tenha sido de mais utilidade, a AFC testa a força ou coerência das estruturas latentes e identifica o grau de associação entre elas. Nossa análise concentra-se em um único conceito, legitimidade do regime, que nossa teoria herdada nos diz que tem várias subdimensões inter-relacionadas. Nós queríamos muito "ver" graficamente essas relações, o que a AFC permite. Em suma, a AFC propicia um meio adequado de examinar a validade do constructo da legitimidade democrática.

Os principais resultados essenciais de nossa análise fatorial confirmatória sobre as normas de legitimidade/apoio estão representados na Figura 2. No gráfico, os nomes das variáveis em caixas retangulares indicam variáveis individuais que contribuem para cada dimensão latente. As dimensões latentes são indicadas dentro de círculos e posicionadas à direita das caixas das variáveis. As setas das variáveis para as dimensões representam as trajetórias significantes de relação ${ }^{15}$. Os coeficientes ao lado da seta entre cada variável e sua dimensão latente indicam a correlação entre a estrutura latente e a própria variável. O ajuste total do modelo, tal como medido pelo CFI, foi de 0,878, com 25 variáveis observadas e 31 variáveis nãoobservadas.

\footnotetext{
15 Trajetórias não significantes no nível 0,01 foram eliminadas. Trajetórias com coeficientes menores que 0,01 contribuíam pouco para a análise, mas acrescentavam várias linhas e setas que tornariam a leitura do diagrama difícil demais para justificar o aumento da complexidade.
} 
Figura 2

Análise fatorial confirmatória dos itens de legitimidade

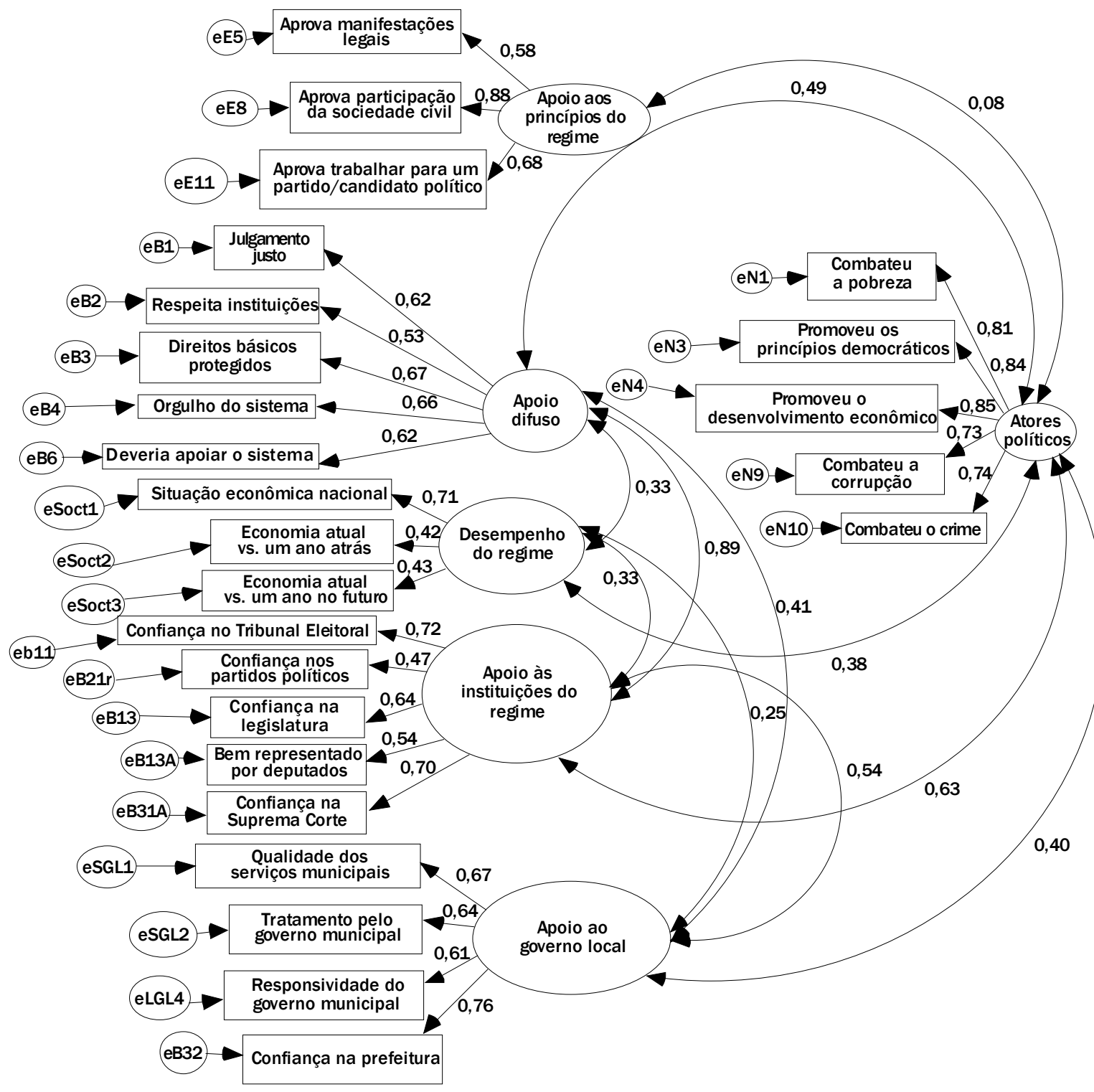

Os termos de erro para as variáveis estão indicados no lado esquerdo da figura, com setas que ligam os termos a suas respectivas variáveis.

Ajuste do modelo: $\mathrm{CFI}=0,878,<0,001$. Todas as trajetórias significantes em $<0,001$ exceto princípios do regime/atores políticos $=0,007$. Todas as trajetórias não significantes $(>0,01)$ foram eliminadas. 
A seqüência da análise desses resultados prosseguiu em três estágios. Primeiro, discutimos cada uma das dimensões e comentamos sobre os coeficientes, para termos uma compreensão clara da questão central de nossa análise, a saber, a dimensionalidade da legitimidade/apoio. Depois, examinamos em detalhe a relação entre os fatores latentes para compreender melhor como essas dimensões se relacionam mutuamente. Por fim, examinamos os graus relativos de apoio para cada uma das dimensões da legitimidade a fim de determinar se, tal como predito na literatura, referentes mais gerais e distantes têm maior apoio do que dimensões que se referem a referentes mais específicos e próximos.

A estrutura das dimensões - 0 primeiro e mais importante resultado confirma que a legitimidade tem múltiplas dimensões baseadas nas orientações dos cidadãos em relação a vários objetos políticos. A Figura 2 revela seis dimensões de legitimidade na Costa Rica agrupadas em torno de referentes/variáveis. Primeiro, quatro estruturas latentes correspondem diretamente a dimensões preditas por Norris e companhia - apoio a princípios do regime, apoio ao desempenho do regime, apoio às instituições do regime e apoio aos atores políticos.

A Figura 2 revela também uma variante na estrutura dimensional da legitimidade não esperada por Norris e companhia. A AFC confirmou a existência na Costa Rica de duas dimensões de apoio institucional nacional, em vez de uma única estrutura latente ${ }^{16}$. Uma dessas dimensões institucionais se refere a várias instituições em separado (por exemplo, a legislatura, os partidos), enquanto que a outra evoca avaliações do funcionamento mais generalizado de instituições (ver os itens listados na Tabela 1 para os enunciados). Para fazer a distinção entre essas dimensões, chamamos a primeira, tal como Norris, de apoio às instituições do regime e a segunda, chamamos de apoio difuso, de modo consistente com a terminologia empregada no trabalho de Muller e Seligson em que também os mesmos itens se agrupam (MULLER, JUKAM e SELIGSON, 1982; SELIGSON, 1983). Desse modo, o apoio às instituições do regime consiste nas avaliações pelos cidadãos de várias instituições costarriquenhas específicas - Supremo Tribunal Eleitoral, Suprema Corte e Assembléia Legislativa - e de partidos políticos e deputados do próprio respondente. $\mathrm{O}$ apoio difuso consiste em cinco referentes institucionais que avaliam a justeza dos julgamentos, as instituições e o sistema político em geral, a proteção dos direitos básicos e o apoio dos cidadãos ao sistema político. A AFC confirma assim que o conjunto de variáveis das instituições do regime em nível nacional se divide, na verdade, em dois subconjuntos, como indicamos aqui. Cada estrutura é razoavelmente coerente em seu interior (coeficientes variável-dimensão variando entre 0,47 e 0,72 para instituições do regime e entre 0,53 e 0,67 para apoio

\footnotetext{
${ }^{16}$ Encontramos os mesmos resultados em nossa análise fatorial exploratória inicial.
} 
difuso). Porém, notamos também que as duas dimensões reveladas se associam intimamente uma à outra $(0,89)$, sugerindo que a distinção entre elas não deve ser exagerada. Pode haver pouco ganho empírico com a separação das medidas mais abstratas das mais concretas de apoio institucional. Isso será algo que valerá a pena examinar quando se olhar para os correlatos das dimensões da legitimidade reveladas neste artigo.

Outra nova dimensão da legitimidade institucional revelada na Figura 2 está baseada no apoio ao governo local dos cidadãos na Costa Rica. Essa dimensão não foi prevista por Norris e companhia e define um novo, embora não surpreendente, objeto de apoio relacionado aos governos municipais costarriquenhos, chamados de cantões. Apesar da sabedoria do antigo clichê que diz que "toda política é local", a pesquisa em ciência política ignora com freqüência este nível. É o que costuma acontecer nas pesquisas sobre países muito centralizados, como os da América Latina, especialmente sobre os não-federativos, que constituem a maioria dos $\operatorname{casos}^{17}$. A dimensão de apoio às instituições do governo local aqui encontrada é claramente coerente (os coeficientes das variáveis com a estrutura latente variam de 0,61 a 0,76).

Desse modo, encontramos uma forte dimensão da legitimidade do governo local e acreditamos que sua ausência de quase todos os estudos que examinam o apoio ao sistema político não se justifica mais, exceto nos casos em que os governos locais não existem ou são completamente irrelevantes. Isso vale especialmente se levarmos em conta as evidências crescentes de que a legitimidade do governo local afeta significativamente outras atitudes e comportamentos. Seligson e Córdova (1995) relatam que o maior apoio às instituições do governo local em El Salvador levou, em uma análise por mínimos quadrados em dois estágios, a um apoio maior ao governo nacional. Booth e Seligson (no prelo) relatam que os cidadãos costarriquenhos com maior apoio ao governo local votaram mais e se engajaram mais na sociedade civil.

As cinco variáveis que medem a avaliação pelos costarriquenhos do desempenho dos atores políticos também indicam coerência substancial, associandose com a estrutura latente entre 0,73 e 0,85. Esse conjunto de itens pede que os respondentes avaliem o desempenho do presidente no poder.

Relação entre fatores latentes - Empreendemos agora a segunda tarefa, uma exploração das relações entre os fatores latentes. Primeiramente observamos, tal como era esperado, que a AFC revela que a maioria das seis dimensões da legitimidade democrática encontradas na Costa Rica estão positivamente relacionadas umas com as outras e muitas dessas relações são estatisticamente significantes. Das quinze relações

\footnotetext{
17 México, Argentina e Brasil são os únicos sistemas federativos da América Latina.
} 
diádicas possíveis entre cada uma das seis dimensões e as outras cinco, onze têm coeficientes de associação significativos (indicados pelas setas de duas pontas na Figura 2).

A associação mais forte $(0,89)$ entre estruturas latentes ocorre entre apoio às instituições do regime e apoio difuso. Isso não surpreende pois, de início, esperava-se que essas dimensões constituíssem uma única. As próximas associações mais fortes são aquelas entre apoio às instituições do regime e apoio aos atores políticos $(0,63)$, apoio às instituições do regime e apoio ao governo local $(0,54)$ e apoio difuso e apoio aos atores políticos $(0,49)$. Aqui observamos um padrão de associações de forte a moderadas entre as orientações dos costarriquenhos para suas instituições políticas formais e os ocupantes delas. Parece-nos que esse padrão harmoniza-se com o que se poderia esperar de cidadãos em um sistema democrático que há cinco décadas é estável e bem institucionalizado.

As associações restantes entre pares de dimensões são, em ordem decrescente de força: apoio difuso e apoio ao governo local $(0,41)$, apoio aos atores políticos e apoio ao governo local $(0,40)$, apoio aos atores e desempenho do regime $(0,38)$, apoio difuso e desempenho do regime $(0,33)$, desempenho do regime e apoio às instituições do regime $(0,33)$ e desempenho do regime e governo local $(0,25)$. Vários desses conjuntos de pares de dimensões envolvem a avaliação de partes do sistema bastante especificadas e particulares - governo local, atores (o presidente), desempenho (econômico) do regime. Na época de nosso survey, vários desses objetos de avaliação estavam operando com graus variados de eficiência. Havia escândalos de corrupção, fraco desempenho econômico e governos municipais enfraquecidos. Não nos surpreende ver que essas dimensões específicas apresentam correlações menores entre elas e com dimensões mais abstratas, como apoio difuso.

As associações mais fracas entre as estruturas latentes são aquelas que não conseguiram obter significância estatística (no nível 0,01) e, por isso, não estão representadas na Figura 2 por setas de duas pontas entre dimensões. Essas quatro dimensões envolvem o apoio aos princípios do regime, que se relaciona significativamente somente com uma das outras cinco dimensões, e mesmo assim em apenas 0,08 . Tendo em vista a importância atribuída ao apoio aos princípios do regime na literatura sobre legitimidade, nos impressionamos com esse baixo grau de associação com o resto das dimensões da legitimidade.

Essa fraca associação entre princípios do regime e as outras dimensões da legitimidade deriva provavelmente, pelo menos em parte, dos relativamente altos valores totais na escala em seus itens componentes (Tabela 1). A maioria dos costarriquenhos expressa forte apoio a esses três princípios democráticos que fundamentam os direitos de participação política. Não esperaríamos necessáriamente esse resultado em outras democracias menos consolidadas (por exemplo, na 
Guatemala), onde há, quase com certeza, maior divergência de opinião e menos apoio total a esses itens do que na Costa Rica. Esse resultado ilustra e sustenta nosso argumento de que é importante examinar a estrutura da legitimidade em um país de cada vez, em vez de realizar uma análise com muitas nações agrupadas. Ao mesmo tempo, se na Costa Rica os princípios do regime não estão conectados a nenhuma das outras dimensões da legitimidade, exceto em uma ligação muito tênue com o apoio aos atores políticos, é importante reavaliar a proeminência atribuída a essa dimensão. Em outras palavras, parece-nos que a legitimidade do regime está, em larga medida, desconectada da crença do cidadão nos princípios democráticos básicos. Esse resultado tem grande repercussão em nossas teorias da democracia e do papel dos valores democráticos.

Vale a pena recapitular que o apoio ao governo local, nossa dimensão de legitimidade recém-identificada, correlaciona-se com o apoio às instituições do regime, apoio difuso, atores políticos e desempenho do regime. Assim entrelaçado nos contornos da legitimidade política na Costa Rica, não está isolado nem é esotérico, mas uma dimensão integral, com potencial considerável para revelar novas informações. Como já observamos, descobrimos que o apoio ao governo local molda outras atitudes e a participação na Costa Rica e em outros lugares. Isso sugere que, dada a multidimensionalidade da participação política, a legitimidade do governo local pode estar atraindo a participação tanto dos cidadãos apoiadores como dos críticos.

Graus relativos de apoio - A fase final da análise explora os graus relativos de apoio entre as dimensões preditas pela teoria da legitimidade. Esperávamos que os costarriquenhos avaliassem de modo mais positivo os referentes mais abstratos de sua comunidade política nacional e seus princípios governantes. Além disso, esperávamos que eles provavelmente avaliassem de modo menos positivo as instituições do regime mais concretas e o desempenho dos atores de que tivessem mais conhecimento político e maior experiência. A diferença aqui é entre a visão dos costarriquenhos da pátria, de seu governo em geral e da democracia em oposição ao desempenho do presidente no poder, à prefeitura e ao desempenho atual e esperado da economia.

Os dados da Tabela 1, na forma dos escores de cada item e das médias para cada conjunto de variáveis que compõem as dimensões latentes, dão, em geral, suporte a essa hipótese de graus diferentes de apoio por dimensão. A muito abstrata comunidade política (que não incluímos na AFC porque é quase invariante) tem o grau mais alto de apoio, com um escore médio de 90,83. Como o operacionalizamos referenciando-o aos direitos de participação dos cidadãos, o apoio aos princípios centrais do regime tem o segundo mais alto grau de apoio entre os costarriquenhos (média $=79,35$ ). 
Embora muito positivo em média, o nível de apoio começa a declinar para o conjunto seguinte de dimensões. Em comparação com a dimensão dos princípios do regime (média em torno de 79 em 100), os costarriquenhos manifestam um razoavelmente alto apoio difuso às instituições (por exemplo, respeito às instituições, orgulho do sistema), em um escore médio de 69,23 em 100. Porém, à medida que aumenta a especificidade da referência às instituições e atores e situações concretas, as médias para cada conjunto de itens das dimensões caem para níveis muito mais baixos: o apoio específico a instituições do regime fica acima do ponto médio da escala, em 55,59. Mas bem abaixo desse ponto ficam o apoio ao governo local $(46,44)$, o apoio aos atores políticos $(46,69)$ e a avaliação do desempenho (econômico) do regime $(41,27)$.

Desse modo, os costarriquenhos percebem a existência de uma comunidade nacional e apóiam fortemente os princípios da democracia. Eles também são razoavelmente positivos em suas percepções das instituições em geral (apoio difuso). À medida que as instituições são especificadas, o apoio diminui (embora ainda permaneça positivo). Em contraste, suas avaliações do desempenho do governo local, do desempenho (econômico) do regime e dos atores políticos nacionais, em média, tal como esperado, ficam abaixo da metade das escalas de avaliação e bem abaixo das médias para outras dimensões. Assim, à medida que os pontos de referência passam do abstrato (comunidade, democracia, instituições em geral) para o concreto (governo local, desempenho de atores nacionais), as avaliações se tornam mais críticas. Esses resultados são, em larga medida, consistentes com as discussões teóricas que balizam a pesquisa sobre legitimidade.

Como se compara o apoio político dos costarriquenhos com o dos cidadãos de outras democracias? A análise que Dalton (2004, p. 60-61) fez das médias nacionais para quatro dimensões da legitimidade em oito nações oferece alguns pontos de referência interessantes ${ }^{18}$. Tal como os cidadãos dos Estados Unidos, mas de forma oposta a alemães e japoneses, os costarriquenhos compartilham percepções muito altas da existência de uma comunidade política nacional. Eles se parecem com noruegueses, alemães, suecos e americanos no apoio às instituições nacionais e aos princípios centrais do regime. Enquanto os noruegueses manifestam graus extremamente altos de apoio aos atores políticos, o apoio dos costarriquenhos a esses atores (tal como o dos alemães, australianos e americanos) fica um pouco abaixo do ponto médio da escala.

\footnotetext{
18 As dimensões de Dalton são denominadas de modo levemente diferente das nossas mas, para o propósito de comparação, os nomes de suas dimensões são listados a seguir, tendo ao lado, entre parênteses, a nossa formulação: apoio à comunidade (comunidade política), valores democráticos (apoio a princípios centrais do regime), apoio às instituições (apoio às instituições do regime e apoio difuso) e apoio à autoridade (apoio aos atores políticos).
} 


\section{Conclusões}

Utilizando um survey de amostra nacional entre os cidadãos costarriquenhos projetado para explorar a legitimidade, testamos em detalhe o constructo de legitimidade política predito por Easton e elaborado por Norris. Empregamos múltiplos itens, em vez de únicos, para cada objeto de apoio previsto, a fim de fortalecer nossa confiança na validade das dimensões preditas. Usamos análise fatorial exploratória e depois confirmatória para explorar a estrutura dimensional da legitimidade democrática e descobrimos que o modelo de legitimidade de Easton, tal como emendado por Norris, Dalton e outros existe mais ou menos como foi predito. As várias dimensões da legitimidade do sistema político estão organizadas em torno da avaliação de objetos do sistema político que vão do abstrato e geral (uma comunidade política nacional, princípios do regime democrático) ao mais concreto (desempenho do regime, instituições governamentais específicas e atores políticos no poder). Essas dimensões da legitimidade (exceto para a comunidade política) são razoavelmente coerentes em termos das médias e desvios padrão observados dos itens componentes e dos coeficientes de associação das variáveis com as dimensões latentes, isoladas por meio de análise fatorial confirmatória. Além disso, mais de dois terços das dimensões da legitimidade correlacionam-se positivamente umas com as outras, tal como esperado. A única dimensão menos relacionada às outras, talvez devido a seus níveis relativamente baixos de variância, é o apoio aos princípios centrais do regime. Esse resultado sugere que é preciso alguma reconsideração da estrutura da legitimidade, uma vez que uma de suas dimensões clássicas não está relacionada com as outras em nossos dados da Costa Rica. Isso talvez seja função de alguma excepcionalidade da Costa Rica, mas não pensamos assim. Ao contrário, consideramos que as tentativas anteriores de captar essas dimensões com perguntas que achamos que não a captam de modo adequado, foram provavelmente enganadoras e, portanto, é necessário aprofundar o trabalho conceitual e de medição.

Tal como previsto em uma democracia estável e bem estabelecida, e de modo consistente com as predições teóricas, encontramos uma estrutura de normas de legitimidade coerente e hierárquica. Os níveis médios de avaliação ou apoio dos costarriquenhos aos objetos políticos da legitimidade são mais altos para as abstrações da comunidade nacional e dos princípios democráticos. Os níveis médios de avaliação diminuem para um apoio médio alto aos referentes mais concretos, tais como apoio difuso e instituições específicas, e caem ainda mais no que tange ao desempenho de atores específicos, governo local e desempenho do regime.

Descobrimos também o que acreditamos que sejam nuances significativas nas estruturas da legitimidade no caso costarriquenho, devido à variedade sem 
precedentes de medidas que conseguimos utilizar e devido à consideração de objetos adicionais de avaliação. Ao perguntar sobre numerosos objetos de avaliação (muitas instituições específicas), encontramos duas dimensões nacionais (instituições do regime, apoio difuso) e uma para o governo local. Portanto, presumimos que haverá provavelmente ricos efeitos locais a serem identificados em cenários nacionais específicos em pesquisas futuras.

Nossas conclusões sugerem quatro caminhos de aprofundamento das pesquisas. Um deles é explorar os contornos da legitimidade política em outros cenários nacionais. Os resultados da Costa Rica confirmam amplamente os de Dalton (2004) para outras democracias bem estabelecidas, embora a história e a economia desse país tenham poucos paralelos com as das democracias industriais avançadas. Seria valioso determinar se a legitimidade nas novas democracias que surgiram na "terceira onda" tem estruturas semelhantes, ou se elas compartilham dimensões da legitimidade distintas. Uma nova confirmação dos padrões de legitimidade encontrados nas democracias mais antigas e na Costa Rica poderia elevar a versão modificada da conceituação de Easton da legitimidade democrática a um status quase axiomático.

Outra direção para pesquisa será procurar e examinar as implicações de outras possíveis dimensões da legitimidade. Já é evidente que objetos antes desconsiderados, como o governo local, podem constituir uma parte significativa da estrutura da legitimidade. Isso sugere que outros traços importantes das sociedades políticas podem justificar mais pesquisas sobre este tema. Suspeitamos, por exemplo, que podem surgir resultados interessantes do exame de instituições estaduais em sistemas federativos ou instituições regionais em sistemas unitários. Acreditamos também que valeria a pena explorar instituições da sociedade civil nãoestatais que integram a sociedade, tais como partidos, meios de comunicação de massa e grupos de interesse. Essas entidades teriam uma estrutura identificável de legitimidade política? Se assim for, como elas podem afetar as ligações dos partidos com a sociedade política?

Uma terceira via de pesquisa seria estudar a legitimidade em outros tipos de regimes. Como são as normas de legitimidade em democracias instáveis ou mesmo em cenários não-democráticos? Nossa experiência indica, no entanto, que realizar surveys com perguntas sobre o desempenho do regime pode ser muito arriscado ou impossível em regimes autoritários ou em cenários políticos altamente voláteis e instáveis. Sabemos também que nas primeiras fases dos regimes pós-autoritários, a não-resposta em surveys pode ser alta, como aconteceu na Espanha pós-Franco (MCDONOUGH et al., 1998). Estudar tais questões pode ser difícil em cenários autoritários, mas tendo em vista a possibilidade de transições importantes em andamento na Ásia e no Oriente Médio, talvez existam oportunidades para fazê-lo. 
Um quarto caminho para as pesquisas, o qual seguiremos em outros trabalhos, é a questão do "e daí?". Legitimidade realmente importa? Sabemos agora que dimensões da legitimidade política existem nas mentes dos cidadãos de algumas nações e que ela possui dimensões não suspeitadas anteriormente. Porém, importa de fato para o mundo político real que a legitimidade exista? Ela altera o panorama político de uma nação? Ela molda de alguma maneira o capital social e político? O declínio observado da legitimidade em muitas sociedades políticas importa de fato em termos de um efeito mensurável sobre os cidadãos ou a sociedade? A legitimidade afeta atitudes operativas críticas, tais como o fato de os cidadãos sustentarem ou não normas democráticas, em vez de autoritárias? Ela molda a participação ou não dos cidadãos na política por meio do voto, do contato com autoridades, do engajamento na sociedade civil, da militância partidária, do engajamento em campanhas eleitorais ou em protestos?

Em outro trabalho (BOOTH e SELIGSON, no prelo), iniciamos esse processo com a investigação do modo como as normas de legitimidade dos costarriquenhos afetam a maneira como eles se engajam na política e interagem com seu governo. Descobrimos que as diversas dimensões da legitimidade não causam efeitos uniformes nos diferentes modos de participação política. Algumas dimensões da legitimidade aumentam certos modos de participação, ao mesmo tempo que diminuem alguns e não têm efeito sobre outros. Por exemplo, com outros fatores mantidos constantes, maiores crença na comunidade política e apoio ao governo local aumentam o exercício do voto e a ativismo societal. O baixo apoio difuso aumenta a militância comunal, enquanto que a baixa confiança nas instituições do regime faz crescer o engajamento na sociedade civil. Uma descoberta nova dessa pesquisa é que duas relações legitimidade-participação são curvilineares. Isso sugere que as teorias e pesquisas anteriores, baseadas em um tratamento unidimensional da legitimidade e em uma concepção binária da participação política, como convencional (dentro do sistema) ou não-convencional (protesto), podem ter distorcido os resultados anteriores. Assim, esperamos empreender mais pesquisas sobre os contornos da legitimidade em outras democracias menos estáveis e mais jovens do que a Costa Rica, e procurar determinar como eles afetam a participação política, o que acreditamos que pode ajudar a responder porque o declínio da legitimidade não levou ao colapso de democracias. 
Anexo A

Análise fatorial de componentes principais com rotação varimax

\begin{tabular}{|c|c|c|c|c|c|c|}
\hline & \multicolumn{6}{|c|}{ Componentes } \\
\hline & 1 & 2 & 3 & 4 & 5 & 6 \\
\hline Orgulho de ser costarriquenho & $-0,014$ & 0,035 & 0,066 & $-0,157$ & 0,054 & 0,630 \\
\hline $\begin{array}{l}\text { Apesar de nossas diferenças, os costarriquenhos } \\
\text { têm muito em comum }\end{array}$ & 0,008 & 0,057 & $-0,024$ & 0,459 & 0,169 & 0,420 \\
\hline Aprova a participação em manifestações legais & 0,048 & $-0,054$ & $-0,021$ & 0,763 & $-0,012$ & $-0,145$ \\
\hline $\begin{array}{l}\text { Aprova a participação na formação de grupos } \\
\text { para resolver problemas da comunidade }\end{array}$ & $-0,139$ & 0,080 & $-0,010$ & 0,855 & $-0,054$ & 0,032 \\
\hline Aprova a participação em campanhas eleitorais & 0,062 & 0,035 & $-0,007$ & 0,813 & $-0,017$ & 0,051 \\
\hline Avaliação da economia nacional & 0,129 & 0,142 & 0,068 & $-0,020$ & 0,559 & $-0,018$ \\
\hline Situação econômica comparada a um ano atrás & 0,001 & 0,084 & 0,020 & $-0,026$ & 0,788 & 0,079 \\
\hline Situação econômica dentro de um ano & 0,080 & 0,039 & 0,032 & 0,035 & 0,782 & 0,052 \\
\hline Julgamento justo & 0,665 & 0,137 & 0,047 & $-0,059$ & 0,025 & 0,019 \\
\hline Respeita as instituições & 0,457 & 0,119 & 0,013 & 0,129 & $-0,045$ & 0,378 \\
\hline Direitos básicos protegidos & 0,686 & 0,028 & 0,084 & $-0,084$ & 0,057 & 0,177 \\
\hline Orgulho do sistema & 0,591 & 0,021 & 0,004 & 0,146 & 0,073 & 0,427 \\
\hline Deveria apoiar sistema & 0,460 & 0,159 & 0,104 & 0,133 & 0,005 & 0,499 \\
\hline Confia no Tribunal Eleitoral & 0,546 & 0,161 & $-0,018$ & 0,203 & $-0,052$ & 0,285 \\
\hline Confia na legislatura & 0,711 & 0,240 & 0,116 & $-0,049$ & 0,079 & $-0,030$ \\
\hline Bem representado por deputados & 0,661 & 0,214 & 0,239 & $-0,098$ & 0,099 & $-0,148$ \\
\hline Confia nos partidos políticos & 0,602 & 0,186 & 0,224 & $-0,112$ & 0,121 & $-0,124$ \\
\hline Confia na Suprema Corte & 0,685 & 0,281 & 0,017 & 0,092 & 0,088 & $-0,019$ \\
\hline Confia na prefeitura & 0,456 & 0,218 & 0,644 & 0,007 & 0,032 & $-0,024$ \\
\hline Qualidade do serviço municipal & 0,084 & 0,095 & 0,817 & $-0,003$ & 0,051 & 0,047 \\
\hline Tratamento pelo governo municipal & 0,064 & 0,032 & 0,779 & $-0,069$ & 0,062 & 0,039 \\
\hline Receptividade oficial do governo municipal & 0,082 & 0,101 & 0,749 & 0,025 & 0,009 & 0,048 \\
\hline Desempenho do regime: combate à pobreza & 0,225 & 0,802 & 0,089 & $-0,019$ & 0,073 & 0,024 \\
\hline $\begin{array}{l}\text { Desempenho do regime: promoção do } \\
\text { desenvolvimento econômico }\end{array}$ & 0,166 & 0,830 & 0,145 & 0,088 & 0,110 & 0,070 \\
\hline $\begin{array}{l}\text { Desempenho do regime: combate à corrupção } \\
\text { no governo }\end{array}$ & 0,226 & 0,823 & 0,112 & $-0,062$ & 0,069 & 0,024 \\
\hline Desempenho do regime: combate ao crime & 0,191 & 0,803 & 0,038 & 0,006 & 0,105 & 0,030 \\
\hline $\begin{array}{l}\text { Desempenho do regime: promoção de princípios } \\
\text { democráticos }\end{array}$ & 0,200 & 0,806 & 0,073 & 0,105 & 0,047 & 0,118 \\
\hline
\end{tabular}

Método de Extração: Análise de Componentes Principais. Método de Rotação: Varimax com Normalização Kaiser. Rotação convergiu em 7 iterações. 
Anexo B

Análise fatorial de componentes principais (matriz estrutural) com rotação oblíqua (OBLIMIN)

\begin{tabular}{|c|c|c|c|c|c|c|}
\hline & \multicolumn{6}{|c|}{ Componentes } \\
\hline & 1 & 2 & 3 & 4 & 5 & 6 \\
\hline Orgulho de ser costarriquenho & 0,082 & $-0,102$ & $-0,068$ & 0,083 & 0,086 & 0,619 \\
\hline $\begin{array}{l}\text { Apesar de nossas diferenças, os } \\
\text { costarriquenhos têm muito em comum }\end{array}$ & 0,087 & 0,495 & $-0,104$ & $-0,023$ & 0,184 & 0,448 \\
\hline Aprova a participação em manifestações legais & 0,031 & 0,746 & 0,028 & $-0,055$ & $-0,028$ & $-0,101$ \\
\hline $\begin{array}{l}\text { Aprova a participação na formação de grupos } \\
\text { para resolver problemas da comunidade }\end{array}$ & $-0,104$ & 0,854 & $-0,066$ & $-0,062$ & $-0,065$ & 0,081 \\
\hline Aprova a participação em campanhas eleitorais & 0,087 & 0,815 & $-0,074$ & $-0,029$ & $-0,014$ & 0,097 \\
\hline Avaliação da economia nacional & 0,170 & $-0,024$ & $-0,220$ & 0,132 & 0,583 & $-0,015$ \\
\hline Situação econômica comparada a um ano atrás & 0,052 & $-0,025$ & $-0,153$ & 0,072 & 0,792 & 0,087 \\
\hline Situação econômica dentro de um ano & 0,121 & 0,033 & $-0,129$ & 0,087 & 0,787 & 0,063 \\
\hline Julgamento justo & 0,675 & $-0,046$ & $-0,296$ & 0,168 & 0,105 & 0,009 \\
\hline Respeita as instituições & 0,518 & 0,173 & $-0,243$ & 0,092 & 0,025 & 0,380 \\
\hline Direitos básicos protegidos & 0,704 & $-0,061$ & $-0,210$ & 0,198 & 0,135 & 0,166 \\
\hline Orgulho do sistema & 0,643 & 0,192 & $-0,194$ & 0,098 & 0,144 & 0,431 \\
\hline Deveria apoiar sistema & 0,553 & 0,185 & $-0,303$ & 0,190 & 0,089 & 0,499 \\
\hline Confia no Tribunal Eleitoral & 0,597 & 0,241 & $-0,299$ & 0,076 & 0,025 & 0,291 \\
\hline Confia na legislatura & 0,737 & $-0,040$ & $-0,416$ & 0,255 & 0,176 & $-0,040$ \\
\hline Bem representado por deputados & 0,677 & $-0,105$ & $-0,385$ & 0,367 & 0,192 & $-0,163$ \\
\hline Confia nos partidos políticos & 0,618 & $-0,118$ & $-0,345$ & 0,342 & 0,205 & $-0,139$ \\
\hline Confia na Suprema Corte & 0,715 & 0,106 & $-0,443$ & 0,153 & 0,180 & $-0,020$ \\
\hline Confia na prefeitura & 0,526 & $-0,007$ & $-0,386$ & 0,726 & 0,136 & $-0,041$ \\
\hline Qualidade do serviço municipal & 0,168 & $-0,025$ & $-0,203$ & 0,827 & 0,121 & 0,029 \\
\hline Tratamento pelo governo municipal & 0,134 & $-0,093$ & $-0,132$ & 0,782 & 0,120 & 0,019 \\
\hline Receptividade oficial do governo municipal & 0,161 & 0,005 & $-0,198$ & 0,757 & 0,075 & 0,032 \\
\hline Desempenho do regime: combate à pobreza & 0,357 & 0,004 & $-0,839$ & 0,218 & 0,190 & 0,014 \\
\hline $\begin{array}{l}\text { Desempenho do regime: promoção do } \\
\text { desenvolvimento econômico }\end{array}$ & 0,318 & 0,112 & $-0,868$ & 0,265 & 0,229 & 0,066 \\
\hline $\begin{array}{l}\text { Desempenho do regime: combate à corrupção } \\
\text { no governo }\end{array}$ & 0,362 & $-0,039$ & $-0,861$ & 0,245 & 0,190 & 0,011 \\
\hline Desempenho do regime: combate ao crime & 0,322 & 0,031 & $-0,831$ & 0,164 & 0,215 & 0,024 \\
\hline $\begin{array}{l}\text { Desempenho do regime: promoção de } \\
\text { princípios democráticos }\end{array}$ & 0,346 & 0,136 & $-0,842$ & 0,193 & 0,164 & 0,116 \\
\hline
\end{tabular}

Método de Extração: Análise de Componentes Principais.

Método de Rotação: Oblimin com Normalização Kaiser. 


\section{Referências Bibliográficas}

ANDERSON, C. J.; GUILLORY, C. A. Political institutions and satisfaction with democracy: a cross-national analysis of consensus and majoritarian systems. American Political Science Review, v. 91, p. 66.81, 1997.

BAKER, C. E.; FERNÁNDEZ P., R.; STONE, S. Z. El Gobierno municipal en Costa Rica: sus características y funciones. San José, Costa Rica: Associated Colleges of the Midwest Central American Field Program e La Escuela de Ciencias Políticas, Universidad de Costa Rica, 1972.

BERMEO, N. G. Ordinary people in extraordinary times: the citizenry and the breakdown of democracy. Princeton, N.J.: Princeton University Press, 2003.

BOOTH, J. A. Political parties in Costa Rica. In: STANSFIELD, D. N. (ed.). Political parties in developing democracies. [2005?]. No prelo.

Costa Rica: quest for democracy. Boulder: Westview Press, 1998.

BOOTH, J. A.; RICHARD, P. B. Repression, participation, and democratic norms in urban Central America. American Journal of Political Science, v. 40, n. 4, p. 1205-1232, november 1996.

BOOTH, J. A.; SELIGSON, M. A. Political legitimacy and participation in Costa Rica: evidence of arena shopping. Political Research Quarterly, v. 59. No prelo.

CANACHE, D. Venezuela: public opinion and protest in a fragile democracy. Miami: North-South Center Press-University of Miami, 2002.

CANACHE, D.; MONDAK, J.; SELIGSON, M. A. Measurement and meaning in cross-national research on satisfaction with democracy. Public Opinion Quarterly, v. 65, n. 4, winter 2001.

CAREY, J. M. Term limits and legislative representation. Cambridge: Cambridge University Press, 1996.

CAYETANO MORA, J. La organización comunal y Dinadeco. San José, Costa Rica: Cambridge University Press, 1996.

CITRIN, J. The political relevance of trust in government. American Political Science Review, v. 68, p. 973-88, 1974. 
CITRIN, J.; MUSTE, C. Trust in Government. In: ROBINSON, J. P.; SHAVER, P. R.; WRIGHTSMAN, L. S. (ed.). Measures of political attitudes. San Diego: Academic Press, 1999. p. 465-532.

CLARK, M. A. Gradual economic reform in Latin America: the Costa Rican experience. Albany, NY: State University of New York Press, 2001.

COHEN, C. Democracy. New York: The Free Press, 1973.

CROOK, R.; MANOR, J. C. Democracy and decentralization in South Asia and West Africa:

participation, accountability, and performance. Cambridge: Cambridge University Press, 1998.

DIAMOND, L. Developing democracy: toward consolidation. Baltimore: Johns Hopkins Press, 1999.

DALTON, R. J. Political support in advanced industrial democracies. In: NORRIS, P. (ed.). Critical citizens: global support for democratic governance. New York: Oxford University Press, 1999. p. 57-77.

Democratic challenges, democratic choices: the erosion of political support in advanced industrial democracies. Oxford: Oxford University Press, 2004.

EASTON, D. A systems analysis of political life. New York: Wiley, 1965.

A re-assessment of the concept of political support. British Journal of Political Science, v. 5, p. $435-57,1975$.

FINKEL, S.; MULLER, E.; SELIGSON, M. A. Economic crisis, incumbent performance and regime support: a comparison of Iongitudinal data from West Germany and Costa Rica. British Journal of Political Science, v. 19, p. 329-51, 1989.

FUCHS, D. The democratic culture of unified Germany. In: NORRIS, P. (ed.). Critical citizens: global support for democratic governance. Oxford: Oxford University Press, 1999.

FUCHS, D.; GUIDOROSSI, G.; SVENSSON, P. Support for the democratic system. In: KLINGEMANN, H.-D.; FUCHS, D. (ed.). Citizens and the State. Oxford: Oxford University Press, 1995. p. 323-53.

GIBSON, J. L.; CALDEIRA, G. A.; SPENCE, L. K. Measuring attitudes toward the United States Supreme Court. American Journal of Political Science, v. 47, n. 2, p. 354-67, 2003. 
HARDIN, R. Do we want trust in government? In: WARREN, M. E. (ed.). Democracy and trust. Cambridge: Cambridge University Press, 1999. p. 22-41.

HISKEY, J.; SELIGSON, M. A. Pitfalls of power to the people: decentralization, local government performance, and system support in Bolivia. Studies in Comparative International Development, v. 37, n. 4, p. 64.88, 2003.

HOLMBERG, S. Down and down we go: political trust in Sweden. In: NORRIS, P. (ed.). Critical citizens: global support for democratic governance. Oxford: Oxford University Press, 1999.

KLINGEMANN, H.-D. Mapping political support in the 1990s: a global analysis. In: NORRIS, P. (ed.). Critical citizens: global support for democratic governance. Oxford: Oxford University Press, 1999. p. 31-57.

KORNBERG, A.; CLARKE, H. D. Citizens and community: political support in a representative democracy. Cambridge: Cambridge University Press, 1992.

KROSNICK, J. A. Maximizing questionnaire quality. In: ROBINSON, J. P.; SHAVER, P. R.; WRIGHTSMAN, L. S. (ed.). Measures of political attitudes. San Diego: Academic Press, 1999. p. 37.58.

LIPSET, S. M. Political man. Baltimore: Johns Hopkins University Press, 1961.

LOWENBERG, G. The influence of parliamentary behavior on regime stability: some conceputal clarifications. Comparative Politics, v. 3, p. 177-200, 1971.

McDONOUGH, P.; BARNES, S. H.; PINA, A. L. The cultural dynamics of democratization in Spain. Ithaca: Cornell University Press, 1998.

MILLER, A. H. Political issues and trust in government. American Political Science Review, v. 68, p. 951.72, 1974.

MISHLER, W.; ROSE, R. Five years after the fall: trajectories of support for democracy in postcommunist Europe. In: NORRIS, P. (ed.). Critical citizens: global support for democratic governance. Oxford: Oxford University Press, 1999. p. 78-99.

MULLER, E. N. Aggressive political participation. Princeton, N.J.: Princeton University Press, 1979. 
MULLER, E. N.; JUKAM, T. O.; SELIGSON, M. A. Diffuse political support and antisystem political behavior: a comparative analysis. American Journal of Political Science, v. 26, p. 240 . 64, 1982.

MULLER, E. N.; WILLIAMS, C. Dynamics of political support-alienation. Comparative Political Studies, v. 13, p. 33-59, 1980.

NICKSON, R. A. Local government in Latin America. Boulder: Lynn Rienner, 1995.

NORRIS, P. (ed.). Critical citizens: global support for democratic governance. Oxford: Oxford University Press, 1999.

Press, 2002.

Democratic phoenix: reinventing political activism. Cambridge: Cambridge University Introduction: the growth of critical citizens? In: NORRIS, P. (ed.). Critical citizens: global support for democratic governance. Oxford: Oxford University Press, 1999. p. 1-27.

NYE, Jr. J. The decline of confidence in government. In: NYE, Jr. J.; ZELIKOW, P. D.; KING, D. C. (ed.). Why people don't trust government. Cambridge: Harvard University Press, 1997. p. 1 . 18.

NYE, Jr. J.; ZELIKOW, P. D. Reflections, conjectures and puzzles. In: NYE, Jr. J.; ZELIKOW, P. D.; KING, D. C. (ed.). Why people don't trust government. Cambridge: Harvard University Press, 1997. p. 253-81.

NYE, Jr. J.; ZELIKOW, P. D.; KING, D. C. (ed.). Why people don't trust government. Cambridge: Harvard University Press, 1997.

PATEMAN, C. Participation and democratic theory. Cambridge: Cambridge University Press, 1970.

PHARR, S. J.; PUTNAM, R. D.; DALTON, R. J. A quarter-century of declining confidence. Journal of Democracy, v. 11, n. 2, p. 5-25, 2000.

PRESTON, R. A.; BRIGGS, E. D.; KORNBERG, A.; CLARKE, H. D. Political support in Canada: the crisis years: essays in honor of Richard A. Preston, a Duke University Center for International Studies publication. Durham, N.C.: Duke University Press, 1983. 
PRZEWORSKI, A.; CHEIBUB, J. A.; ALVAREZ, M. E.; LIMONGI, F. Democracy and development: political institutions and well-being in the world, 1950-1990. Cambridge: Cambridge University Press, 2000.

ROGOWSKI, R. Rational legitimacy: a theory of political support. Princeton: Princeton University Press, 1974.

ROSE, R.; SHIN, D. C.; MUNRO, N. Tensions between the democratic ideal and reality: South Korea. In: NORRIS, P. (ed.). Critical citizens: global support for democratic governance. Oxford: Oxford University Press, 1999.

ROVIRA MAS, J. (ed.). La democracia de Costa Rica ante el siglo XXI. 1. ed. San José, Costa Rica: Editorial de la Universidad de Costa Rica, 2001.

SELIGSON, M. A. On the measurement of diffuse support: some evidence from Mexico. Social Indicators Research, v. 12, p. 1-24, 1983.

Central americans view their local governments, reported to USAID, regional office for urban development and housing. Guatemala City: RHUDO, 1994.

Costa Rican exceptionalism: why the 'Ticos' are different. In: CAMP, R. A. (ed.). Citizen views of democracy in Latin America. Pittsburgh: University of Pittsburgh Press, 2001. p. $90-106$.

The impact of corruption on regime legitimacy: a comparative study of four Latin American countries. Journal of Politics, v. 64, p. 408-33, 2002a.

The renaissance of political culture or the renaissance of ecological fallacy.

Comparative Politics, v. 34, p. 273-92, 2002b.

Trouble in paradise: the impact of the erosion of system support in Costa Rica, 1978. 1999. Latin America Research Review, v. 37, n. 1, p. 160-85, 2002c.

SELIGSON, M. A.; CÓRDOVA, R. El Salvador: entre guerra y la paz, una cultura política en transición. El Salvador: IDELA e FundaUngo, 1995.

SELIGSON, M. A.; GRIJALVA, A.; CÓRDOVA, P. Auditoria de la democracia: Ecuador. Quito, Ecuador: Ediciones CEDATOS, Universidad Andina Simón Bolívar e Universidad de Guayaquil, 2002. 
SELIGSON, M. A.; MULLER, E. N. Democratic stability and economic crisis: Costa Rica 1978. 1983. International Studies Quarterly, v. 31, p. 301-26, 1987.

SUDMAN, S. Probability sampling with quotas. Journal of the American Statistical Association, v. 61, p. 749.71, 1966.

VELIZ, C. The centralist tradition in Latin America. Princeton: Princeton University Press, 1980.

VERBA, S.; NIE, N. H. Participation in America: political democracy and social equality. New York: Harper and Row, 1972.

VERBA, S.; NIE, N. H.; KIM, J. The modes of democratic participation: a cross-national comparison. Beverly Hills: Sage Publications, 1971.

WARREN, M. E. (ed.). Democracy and trust. Cambridge: Cambridge University Press, 1999.

WILSON, B. M. Costa Rica: politics, economics, and democracy. Boulder: Lynne Rienner Publishers, 1998.

Recebido para publicação em novembro de 2005. Aprovado para publicação em março de 2006.

Tradução de Pedro Maia Soares. 